\title{
Neuregulin Signaling Regulates Neural Precursor Growth and the Generation of Oligodendrocytes In Vitro
}

\author{
Viviane Calaora, ${ }^{1}$ Bernard Rogister, ${ }^{2}$ Keren Bismuth, ${ }^{1}$ Kerren Murray, ${ }^{1}$ Heidi Brandt, ${ }^{2}$ Pierre Leprince, ${ }^{2}$ \\ Mark Marchionni, ${ }^{3}$ and Monique Dubois-Dalcq ${ }^{1}$
}

${ }^{1}$ Neurovirologie et Régénération du Système Nerveux, Institut Pasteur, 75724 Paris, France, ${ }^{2}$ Centre de Recherches en Neurobiologie Cellulaire et Moléculaire, Université de Liège, Liège, 4020 Belgium, and ${ }^{3}$ Cambridge NeuroScience, Inc., Norwood, Massachusetts 02139

\begin{abstract}
Neuregulin $1(\mathrm{Nrg}-1)$ isoforms have been shown to influence the emergence and growth of oligodendrocytes, the CNS myelinforming cells. We have investigated how Nrg-1 signaling of ErbB receptors specifically controls the early stages of oligodendrocyte generation from multipotential neural precursors (NPs). We show here that embryonic striatal NPs express multiple Nrg-1 transcripts and proteins as well as their specific receptors, ErbB2 and ErbB4, but not ErbB3. The major isoform synthesized by striatal NPs is a transmembrane type III isoform called cysteine-rich domain Nrg-1. To examine the biological effect of Nrg-1, we added soluble ErbB3 (sErbB3) to growing neurospheres. This inhibitor of Nrg-1 bioactivity decreased mitosis of NPs and increased their apoptosis, resulting in a significant reduction in neurosphere size and number. When NPs were induced to migrate and differentiate by adhesion of neurospheres to the substratum, the level of type III isoforms
\end{abstract}

detected by RT-PCR and Western blot decreased in parallel with a reduction in Nrg-1 fluorescence intensity in differentiating astrocytes, neurons, and oligodendrocytes. Pretreatment of growing neurospheres with sErbB3 induced a threefold increase in the proportion of oligodendrocytes generated from NPs migrating out of the neurosphere. This effect was not observed with an unrelated soluble receptor. Addition of sErbB3 during NP growth and differentiation enhanced oligodendrocyte maturation as shown by expression of galactocerebroside and myelin basic protein. We propose that both type III Nrg-1 signaling and soluble ErbB receptors modulate oligodendrocyte development from NPs.

Key words: neuregulin; neural stem cells; neurosphere growth; oligodendrocyte differentiation; ErbB receptors; embryonic mouse striata
There is much interest in the molecular signals that regulate development of multipotential neural precursors (NPs) and their fate (Edlund and Jessell, 1999). Among candidate regulators are neuregulin 1 (Nrg-1) growth factors and ErbB receptor tyrosine kinases (Carraway and Burden, 1995; Burden and Yarden, 1997). Neuregulins are encoded by a multigene family (NRG-1, -2, -3, and -4), and all Nrg proteins contain an extracellular (EC) epidermal growth factor (EGF)-like domain, which is essential for bioactivity (Adlkofer and Lai, 2000). The NRG-1 gene regulates early development of neurons and myelin-forming cells of the peripheral nervous system and CNS as shown by studies in vitro using recombinant Nrg-1 proteins and through analysis of NRG-1 mutants (Meyer and Birchmeier, 1995; Jessen and Mirsky, 1999; Vartanian et al., 1999; Adlkofer and Lai, 2000). There are at least 15 soluble or transmembrane Nrg-1 proteins that on the basis of different amino termini are grouped as type I [acetylcholine receptor-inducing activity (ARIA) and neu differentiation factor

\footnotetext{
Received Oct. 13, 2000; revised April 2, 2001; accepted April 17, 2001.

This work was supported by Grant 0480/I 16298 of the Multiple Sclerosis Society of Great Britain and Northern Ireland to M.D.-D. and V.C. B.R. and P.L. are Research Associates of the "Fonds National de la Recherche Scientifique" of Belgium (FNRS), which also supported this work. We also thank the Fondation Médicale Reine Elisabeth, Fonds Charcot, the Belgian League against Multiple Sclerosis, and the Concerted Action of the French Belgian Community. We thank Geneviève Rougon and Roberto Bruzzone for critical reading of this manuscript. Dr. Y. Yarden kindly provided the ErbB3 vector (CDM7-IgB-3).

Correspondence should be addressed to Dr. Monique Dubois-Dalcq, Unité de Neurovirologie et Régénération du Système Nerveux, Institut Pasteur, 25 rue du Dr. Roux, 75724 Paris, Cedex 15, France. E-mail: mdalcq@pasteur.fr.

Copyright (C) 2001 Society for Neuroscience $\quad 0270-6474 / 01 / 214740-\bullet \$ 15.00 / 0$
}

(NDF)], type II [glial growth factor 2 (GGF2)], and type III isoforms [sensory-motor derived factor (SMDF) or cysteine-rich domain (CRD-NRG)]. NRG-1 transcripts are found by in situ hybridization in the germinal zone of embryonic day (E) 14 rat and E18 mouse embryos, and the type III transcripts are the most abundant (Corfas et al., 1995; Meyer et al., 1997). In addition, various NRG-1 isoforms are synthesized in vitro by rat sensory neurons, oligodendrocytes, and astrocytes (Raabe et al., 1997; Vartanian et al., 1997; Francis et al., 1999).

How NRG-1 controls early stages of oligodendrocyte development is not clear. Oligodendrocyte progenitors (OPs) are triggered to divide by GGF2, and oligodendrocyte survival is enhanced by NDF and axon-derived Nrg-1 (Canoll et al., 1996; Milner et al., 1997; Raabe et al., 1997; Shi et al., 1998; Fernandez et al., 2000). An increase in oligodendrocyte differentiation was observed in ARIA-treated cultures, whereas GGF2 and NDF inhibited or even reversed their maturation (Vartanian et al., 1994; Canoll et al., 1996, 1999). These contrasting results suggest varying effects of Nrg-1 signaling on oligodendrocyte development, which may depend on the degree of commitment of NPs to the oligodendrocyte fate.

To investigate this question, the neurosphere system appears particularly appropriate (Reynolds and Weiss, 1996; Gritti et al., 1999) because it allows us to study which factors control NP growth, the recruitment of differentiated cells from the NP pool after neurosphere adhesion, and the commitment to oligodendrocyte differentiation. We show here that NPs of the E14 mouse striatum germinative zone and striatal neurospheres mostly syn- 
Table 1. Primer localization and sequences

\begin{tabular}{|c|c|c|}
\hline Domains & Sense & Primer sequences \\
\hline Ig-like domain of types I and II Nrg-1 & Forward & 5'-TGCCTCCCAGATTGAAAGAAATG-3' \\
\hline GGF2 domain of type II Nrg-1 & Forward & 5'-AACCTCAAGAAGGAGGTCAG-3' \\
\hline N-terminal domain of type III Nrg-1 & Forward & 5'-TGAAGTGGGTATTTGTGGAC-3' \\
\hline EGF-like domain & Reverse & 5'-CCATTCACACAGAAAGTTTT-3' \\
\hline Secreted form & Reverse & 5'-GTTAATGTTCTCATGCGACAG-3' \\
\hline Transmembrane type (c) C-terminal form & Reverse & 5'-CTCACTGAATGAGGTTCTCCTC-3' \\
\hline Transmembrane type (a) C-terminal form & Reverse & 5'-GTTTTACAGGTGAATCTATGTG-3' \\
\hline ErbB2 & Forward & 5'-GAGGTGGTGAGCTGACACT-3' \\
\hline ErbB2 & Reverse & 5'-CCTCTGATTGGTTCACATACT-3' \\
\hline ErbB3 & Forward & 5'-AGATCTGCACCATTGACGTC-3' \\
\hline ErbB3 & Reverse & 5'-TAGGTCTAGGTCCAGTTCTG-3' \\
\hline ErbB4 & Forward & TAGGAGTGAAATTGGACACAG-3' \\
\hline ErbB4 & Reverse & 5'-CTTGTCATGCATGGGAGTCA-3' \\
\hline$\beta$-actin & Forward & 5'-GATGACGATATCGCTGCG-3' \\
\hline$\beta$-actin & Reverse & 5'-GTGGCCATCTCCTGCTCG-3' \\
\hline
\end{tabular}

thesize transmembrane type III Nrg-1 isoforms and that these isoforms are downregulated during differentiation. ErbB2 and ErbB4 are expressed during NP growth and differentiation. Using soluble ErbB3 (sErbB3) receptor to inhibit Nrg-1 function, we demonstrate that Nrg-1 controls the growth of NPs, increasing their proliferation and survival. Moreover, soluble ErbB3 pretreatment of growing neurospheres specifically increased the number of oligodendrocytes differentiating from NPs migrating from the spheres. In contrast, addition of Nrg-1 appears to favor a shift from oligodendrocyte to astrocyte generation. We propose that NP growth is stimulated by endogenous type III Nrg-1 and that this growth-promoting effect inhibits oligodendrocyte development, which in turn can be triggered by a soluble ErbB receptor.

\section{MATERIALS AND METHODS}

Preparation of neurosphere cultures. C57-B16 mice $14 \mathrm{~d}$ of age (IFFACREDO) were killed in compliance with animal regulations of the Pasteur Institute. The striata were removed from the embryos and mechanically dissociated before cells were plated, as described previously (Reynolds et al., 1992; Ben-Hur et al., 1998). Briefly, viable cells were seeded at $1.2 \times 10^{5}$ cells $/ \mathrm{ml}$ in uncoated T25 tissue culture flasks (Costar, Cambridge, MA) or in $35 \mathrm{~mm}$ Petri dishes (Falcon, Plymouth, UK). Culture medium consisted of DMEM/F-12 (1:1, v/v) supplemented with B27 (both from Life Technology, Eragny, France) in the presence of 20 $\mathrm{ng} / \mathrm{ml}$ of EGF (Sigma, St. Louis, MO). Media were supplemented with $20 \mathrm{ng} / \mathrm{ml}$ EGF every $2 \mathrm{~d}$, and on every fourth day two-thirds of the media was replaced with fresh media.

Adhesion of neurospheres. After $6 \mathrm{~d}$ in culture, three neurospheres of the same size $(80-100 \mu \mathrm{m}$ in diameter) were plated onto $12 \mathrm{~mm}$ coated coverslips (poly-D-lysine/fibronectin; $10 \mu \mathrm{g} / \mathrm{ml}$ each; Sigma) and $2 \mathrm{ml}$ of serum-free medium without EGF was then added to each well. After $2 \mathrm{~d}$ of adhesion, the majority of cells had migrated out of the sphere.

Neurosphere treatment. Recombinant Human GGF2 (Cambridge NeuroScience Inc., Norwood, MA) was used at 2-200 ng/ml. For experiments with soluble receptors (see description of production and purification below), neurospheres were grown for $6 \mathrm{~d}$ as above in the presence of different concentrations of sErbB3 $(0.1-1 \mu \mathrm{g} / \mathrm{ml})$ or soluble subunit $\beta$ of the glycine receptor (sGlyr; 0.5 or $1 \mu \mathrm{g} / \mathrm{ml}$ ). Every $2 \mathrm{~d}$, EGF, sErbB3, and sGlyr were replenished. In some experiments, GGF2 (100 ng/ml), $\operatorname{sErbB} 3(0.5 \mu \mathrm{g} / \mathrm{ml}$ or $6.6 \mu \mathrm{M})$, and sGlyr $(0.5 \mu \mathrm{g} / \mathrm{ml}$ or $7.6 \mu \mathrm{M})$ were added just after sphere adhesion for $2 \mathrm{~d}$ before immunocytochemical staining.

RT-PCR analysis. Total RNA was purified with an RNAble kit (Eurobio, Les Ulis, France) from E14 striata, adult spinal cord, immortalized Schwann cell cultures (MSC80; courtesy of A. Baron-Van Evercooren, la Salpêtrière, Paris, France), or neurospheres cultured in suspension for
$6 \mathrm{~d}$ or after $6 \mathrm{~d}$ of adhesion. Seven micrograms of total RNA were used in RT reactions using Superscript II (Life technologies, Gaithersburg, MD). One microliter of a 1:7 dilution of the cDNA synthesized from the RT reaction was subjected to PCR in a $50 \mu \mathrm{l}$ reaction with $0.2 \mathrm{mM}$ dNTP, $1.5 \mathrm{mM} \mathrm{MgCl}_{2}, 0.5 \mathrm{~mm}$ primers, and $1 \mu \mathrm{l}(3.5 \mathrm{U})$ of $\mathrm{Taq}$ polymerase (Expand High Fidelity PCR system, Roche, Meylan, France). Primers used to analyze NRG-1 mRNAs encoding different isoforms are described in Table 1 and localized in Figure 1. Reactions were run on a Perkin-Elmer 2400 thermocycler (Roissy-Charles de Gaulle, France) (30 cycles; $94^{\circ} \mathrm{C}$ for $2 \mathrm{~min}, 94^{\circ} \mathrm{C}$ for $15 \mathrm{sec}, 53^{\circ} \mathrm{C}$ for $30 \mathrm{sec}, 68^{\circ} \mathrm{C}$ for $3 \mathrm{~min}$, and a final extension time at $72^{\circ} \mathrm{C}$ for $7 \mathrm{~min}$ ).

Specific primers designed to amplify ErbB2, ErbB3, and ErbB4 are listed in Table 1. cDNA synthesized by RT was diluted at 1:2 before PCR amplification, then processed as described above with an annealing temperature of $60^{\circ} \mathrm{C}$. $\beta$-Actin was used as a control target sequence for all amplifications.

Western blot. Proteins were extracted as described by Raabe et al. (1996) from mouse E14 striata, floating or adhering spheres, and cultured Schwann cells. Equivalent amounts of extracted proteins $(15 \mu \mathrm{g})$ were loaded on each lane of a $10 \%$ polyacrylamide gel (or $7.5 \%$ for the anti-ErbB blots). After electrophoresis, proteins were transferred to a polyvinylidene difluoride membrane (Roche). The membrane was incubated with primary antibody overnight at $4^{\circ} \mathrm{C}$ and then with a secondary antibody conjugated with peroxidase for $1 \mathrm{hr}$ at room temperature. After extensive washes, immunoreactive bands were visualized by enhanced chemoluminescence (SuperSignal WestPico, Pierce, Brussels, Belgium or ECL, Amersham Pharmacia, Buckinghamshire, UK). Primary antibodies used were HRG-C19 goat polyclonal anti-Nrg-1 (Santa Cruz Biotechnology, Santa Cruz, CA; 1:1000), goat IgG antibody against recombinant human SMDF (R\&D systems, Abingdon, UK; 1:500), and rabbit polyclonal antibodies against the cytoplasmic domain of ErbB receptors (Santa Cruz Biotechnology), the precursor form of human ErbB2 (Neu, C-18; 1:500), ErbB3 (C-17, 1:500), and ErbB4 (C-19; 1:500). Secondary antibodies conjugated with peroxidase were RG-16 mouse monoclonal anti-rabbit Ig (Sigma) used at 1:3000 and rabbit anti-goat IgG (Sigma) used at 1:8000. Human recombinant SMDF $(\mathrm{R} \& D)(10 \mathrm{ng}$ per lane) was used as control.

Immunocytochemistry of tissues and cells. The following antibodies were used at the indicated dilution: goat polyclonal antibody to the $\mathrm{C}$ terminus of the mature form of human Nrg-1 (HRG-C19; 1:200) and rabbit polyclonal antibody to the $\mathrm{C}$ terminus of the precursor form of human Nrg-1 (HRG-C20; 1:200) were obtained from Santa Cruz Biotechnology. The rabbit polyclonal antibodies against the cytoplasmic domain of the precursor form of human ErbB2 (Neu, C-18; 1:100) and ErbB4 (C-19; 1:100) were also from Santa Cruz Biotechnology. Control antibodies for Nrg-1 and ErbB staining were non-immune goat and rabbit $\mathrm{IgG}$ used at the same final concentration (Jackson ImmunoResearch Laboratories, West Grove, PA). TujI is a mouse $\mathrm{IgG}_{2}$ a antibody against neuron-specific class III $\beta$-tubulin (Babco, Richmond, CA; 1:500). The rabbit polyclonal (1:200) and the mouse $\operatorname{IgG}_{1}(1: 100)$ antibodies to glial 
fibrillary acidic protein (GFAP) were purchased from Dako (Glostrup, Denmark) and Chemicon (Temecula, CA), respectively. Preoligodendrocytes were identified with mouse $\operatorname{IgM}$ antibodies $\mathrm{O} 4$ (a gift from $\mathrm{S}$. Barnett, Glasgow, Scotland; 1:20) and oligodendrocytes with O1 IgM antibodies against galactocerebroside (a gift from R. Cohen, National Institutes of Health; 1:5), and rabbit polyclonal antibody to myelin basic protein (MBP; 1:50) was from Zymed laboratories (San Francisco, CA). The nuclear marker DAPI $(0.1 \mu \mathrm{g} / \mathrm{ml}$ final) was from Sigma (Paris, France).

Cryosections $(10 \mu \mathrm{m})$ on Superfrost Plus glass slides (Menzel-Glaser, Braunschweig, Germany) were prepared from striata of E14 mice or from floating neurospheres that had been fixed in $4 \%$ paraformaldehyde in PBS overnight at $4^{\circ} \mathrm{C}$. Adherent neurospheres were fixed the same way for $30 \mathrm{~min}$ at room temperature before staining. Primary antibodies were applied overnight at $4^{\circ} \mathrm{C}$ or $30 \mathrm{~min}$ at room temperature (O4 staining) in a humidified chamber. Slides were then incubated in appropriate secondary antibodies and with DAPI for $30 \mathrm{~min}$ at room temperature. For intracellular labeling with HRG-C19, HRG-C20, ErbB2, and ErbB4 antibodies, a permeabilization with PBS $0.1 \%$ Triton X-100 was performed for $20 \mathrm{~min}$ at room temperature before blocking with normal goat serum. Double and triple immunolabeling were performed as described previously (McKinnon et al., 1990; Ben-Hur et al., 1998).

Preparations were photographed with a Leica microscope (DMRB model) equipped with a Coolsnap camera system (Princeton Instruments, Evry, France). For the confocal analysis, a Leica Optovar inverted microscope equipped with a Leica model TCSAD Confocal Instrument was used (courtesy of E. Perret, Department of Retrovirology, Pasteur Institute, Paris).

Purification of soluble receptors. The soluble form of ErbB3 receptor was constructed using the ectodomain of ErbB3 cloned in frame to an Fc portion (hinge, $\mathrm{CH} 2$, and $\mathrm{CH} 3$ domains) of human immunoglobulin $\mathrm{G}$, called CDM7-IgB-3, courtesy of Y. Yarden (Chen et al., 1996). The sequence coding for the ectodomain was released by a BamHI and EcoRV digestion and purified on an agarose gel. The purified DNA fragment was then ligated in frame in a Bam HI-EcoRV-digested pCDNA3-Myc-His vector (Invitrogen, Groningen, The Netherlands). The rat glycine receptor $\beta$ subunit (sGlyr) was cloned by RT-PCR from adult rat spinal cord RNA using primer with an ApaI site underlined (forward: AACGGGCCCGTTTTCAAGATGAAGTTTTCGTTG; reverse: TTCGGGCCCTAAATATATAGACC). The resulting PCR product was purified on an agarose gel and cloned in a pCR-TOPO vector (Invitrogen). The sGlyr was then subcloned in pCDNA3-Myc-His vector in $A p a \mathrm{I}$ sites. The various constructs and their orientation were verified by sequencing. The constructs were transfected into Chinese hamster ovary $(\mathrm{CHO})$ cells using the DAC30 lipofection reagent (Eurogentec, Liège, Belgium) selected with G418 at $500 \mu \mathrm{g} / \mathrm{ml} 48 \mathrm{hr}$ later (Life Technologies, Gent, Belgium). Selected recombinant $\mathrm{CHO}$ cells were then cloned by dilution, and several clones were tested and selected for the expression of the ectodomain of ErbB3 in the cytoplasm.

We extracted $40 \times 10^{6}$ cells in $40 \mathrm{ml}$ of an ice-cold buffer containing $8 \mathrm{M}$ urea, $0.1 \mathrm{M} \mathrm{NaH}_{2} \mathrm{PO}_{4}$, and $0.01 \mathrm{M}$ Tris, $\mathrm{pH}$ 8.0. Cells were homogenized in a Potter tissue homogenizer and then centrifuged for $15 \mathrm{~min}$ at $15,000 \times \mathrm{g}$ at $4^{\circ} \mathrm{C}$. The supernatant was loaded on an Ni-NTA column (Qiagen, Westburg, Leusden, The Netherlands) equilibrated with extraction buffer. The use of urea as a denaturing agent resulted in enhanced attachment of recombinant sErbB3 to Ni-NTA and therefore increased the yield of purification. After loading, the column was washed with a $0-100 \%$ gradient of refolding solution ( $0.02 \mathrm{M}$ Tris, $\mathrm{pH} 7.4,500 \mathrm{~mm} \mathrm{NaCl}$, and $20 \%$ glycerol) at $0.5 \mathrm{ml} / \mathrm{min}$ for $90 \mathrm{~min}$. Two steps of elution were performed in refolding solution containing successively 10 and $250 \mathrm{~mm}$ imidazole. sErbB3 was present in the last elution step as demonstrated by Western blotting using anti-myc antibodies (see Fig. 4A). sGlyr was purified as described for sErbB3 on Ni-NTA gel except that the extraction buffer also contained $0.25 \%$ sodium deoxycholate. The refolding step was replaced by a wash in extraction buffer adjusted to $\mathrm{pH}$ 6.3, and the elution was performed with extraction buffer adjusted to $\mathrm{pH} 4.5$ and containing 2\% 3-[(3-cholamidopropyl)dimethylammonio]-1-propanesulfonic acid. sGlyr was selectively eluted as demonstrated in Figure $4 A$ and appeared as a $75 \mathrm{kDa}$ species. The higher than predicted molecular weight (MW) is probably attributable to the MW of the Tag $(6.7 \mathrm{kDa})$ and glycosylation. Silver gel performed at the end of each soluble receptor purification did not reveal any contaminant. To test the biological activity of sErbB3, a tritiated thymidine assay was run on rat Schwann cells (Mahanthappa et al., 1996; Keirstead et al., 1999) cultured in the presence of increasing doses of sErbB3 alone or with $20 \mathrm{ng} / \mathrm{ml}$ of GGF2.
Cell proliferation assay. Two different assays were used. First, the neurospheres were grown in suspension for different times and in the presence of $10 \mu \mathrm{M}$ bromodeoxyuridine (BrdU; Sigma) for the last $24 \mathrm{hr}$. These spheres were plated on poly-D-lysine/fibronectin-coated coverslips for $30 \mathrm{~min}$ at $37^{\circ} \mathrm{C}$ to allow neurosphere adhesion but not differentiation. Neurospheres were then fixed for $30 \mathrm{~min}$ at room temperature. The spheres were then processed for BrdU staining (Ben-Hur et al., 1998) with a mouse $\operatorname{IgG}_{1}$ against BrdU from Becton Dickinson (San Jose, CA; 1:50) and colabeled with DAPI.

Second, the 3-(4,5-dimethylthiazol-2-yl)-2,5-diphenyl tetrazolium bromide (MTT; Sigma) reduction assay (Mosmann, 1983) was used to test the effect of exogenous Nrg-1 on NP growth. We cultured 1000 viable cells $/ \mathrm{ml}$ in $96-$ well plates in the presence of 2,20 , or $200 \mathrm{ng} / \mathrm{ml}$ of GGF2 for $2 \mathrm{~d}$ before addition of MTT at $1 \mu \mathrm{g} / \mathrm{ml}$. After $4 \mathrm{hr}$ at $37^{\circ} \mathrm{C}, 100 \mu \mathrm{l}$ of dissolving solution (20\% SDS, 1:2 dimethyl formamide, $2 \%$ acetic acid, $0.06 \% \mathrm{HCl} 1 \mathrm{~N}$ ) was added to the wells. The plates were incubated for 20 $\mathrm{min}$ at room temperature for color development and then assayed by measuring the optical density (O.D.) at $570 \mathrm{~nm}-$ O.D. at $630 \mathrm{~nm}$. Background absorbance of medium in the absence of cells was subtracted.

TUNEL analysis. TUNEL method was used to label apoptotic nuclei in floating neurospheres as described previously (Gavrieli et al., 1992). Briefly, after 2 or $6 \mathrm{~d}$ in culture, floating neurospheres were adhered 30 min as above, then fixed and permeabilized for 40 min with $0.5 \%$ Triton $\mathrm{X}-100$ in PBS. Cells were then incubated for $10 \mathrm{~min}$ in terminaldeoxynucleotidyl-transferase (TdT) buffer (Roche) before incubation with TdT and biotin-labeled dUTP (Roche) for $30 \mathrm{~min}$ at $37^{\circ} \mathrm{C}$. Finally, biotin was revealed by streptavidin-Cy3 and colabeled with DAPI.

Statistics. For each experimental condition, cell counting was performed blind in three independent experiments. The total number of spheres and the size of 50 floating neurospheres in triplicate Petri dishes were analyzed with a Leica microscope (DMIL) equipped with a graduated eye-piece. To determine the percentages of BrdU- and TUNELpositive cells in each experiment, all cells in 30 spheres per slide were counted with a Leica microscope (DMRB model). In experiments with adherent neurospheres, we counted the number of each type of differentiated cells and the total number of cells per sphere. In the latter case, we scanned the DAPI staining of the entire sphere outgrowth with the Coolsnap camera and counted the nuclei with NIH Image software (Version 1.62).

The mean fluorescence per cell of Nrg-1 expression was measured for NPs and differentiated cells with NIH image software on confocal images of neurospheres stained with either HRG-C20 or HRG-C19 antibodies. Data points from the MTT assay were averages from five independent experiments. All values are shown as mean \pm SEM. The statistical significance of differences between control and experimental conditions was analyzed using the one-tailed Student's $t$ test (Excel 98). A value of $p<0.05$ is considered statistically significant $\left({ }^{*} p<0.05 ;{ }^{* *} p<\right.$ $0.02 ; * * * p<0.01)$.

\section{RESULTS}

To study Nrg-1 signaling in multipotential NPs, we isolated the striatal periventricular zone of E14 mouse embryos and cultured the dissociated cells as neurospheres (Svendsen and Rosser, 1995; Reynolds and Weiss, 1996). These striatal NPs express nestin and form spheres after growth in EGF for $6 \mathrm{~d}$. When neurospheres are plated onto polylysine/fibronectin-coated coverslips without EGF, NPs migrate out of the spheres and differentiate into cells of the astrocytic, neuronal, and oligodendrocytic lineages. We will first describe which Nrg-1 isoforms and receptors are expressed and then the biological effects of Nrg-1 endogenous signaling in this system.

\section{Neuregulin 1, ErbB2, and ErbB4 are expressed in E14 striatum and neurospheres}

We first characterized by RT-PCR and Western blot which Nrg-1 isoforms were expressed in striatum and in neurospheres. We designed sets of primers that distinguish between the different amino termini of type I and/or II as well as type III isoforms by positioning the forward primer in regions specific for each amino terminus and positioning the reverse primer in the EGF-like 
A

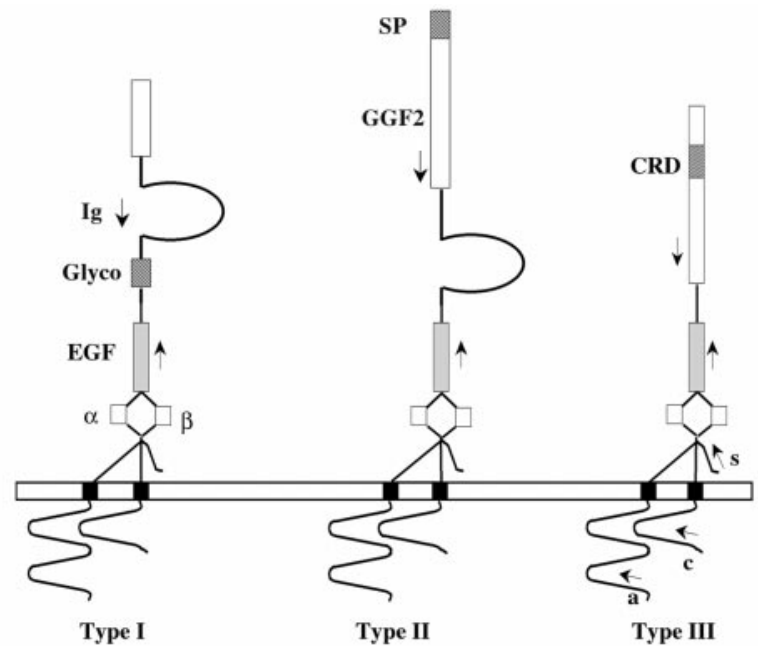

B
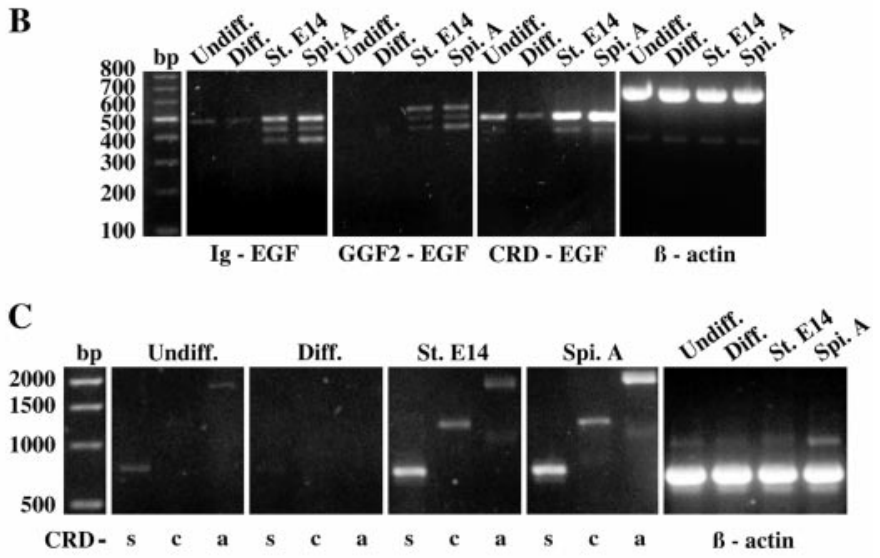

D

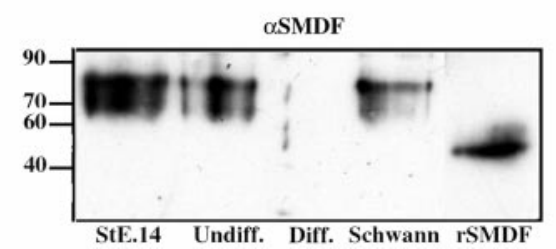

Figure 1. RT-PCR and Western blot analysis of NRG-1 isoforms in E14 striatum and neurospheres. $A$, Schematic representation of the different splice variants of the NRG-1 gene modified from Adlkofer and Lai (2000). The domains where the forward and reverse primers were placed are shown by arrows. For type I, the forward primer was placed in the Ig-like domain $(I g)$, for type II in the amino terminus GGF2 domain $(G G F 2)$ (signal peptide, $S P$ ), and for type III in the CRD region $(C R D)$. Each primer was used in combination with a reverse primer specific for the EGF-like domain $(E G F)$ common to all NRG-1 isoforms $(B)$. To identify the different type III forms, the CRD primer was combined with one located in the short extracellular $\mathrm{C}$-terminus domain of soluble isoforms $(s)$ or with primers able to identify the long and short transmembrane domains because of their location in the C-terminus tail ( $a$ or c) (C). B, Total RNA of neurospheres grown for $6 \mathrm{~d}$ (Undiff.) or after an additional $6 \mathrm{~d}$ of adhesion (Diff.) was subjected to RT-PCR and compared with E14 mouse striata (St. E14). Adult spinal cord (Spi. A) was used as control. The $I g-E G F$ primers gave a very weak band of $480 \mathrm{bp}$ for type I and II isoforms in neurospheres, whereas the signal was somewhat stronger in striata and spinal cord and made of three different bands. Type II NRG-1 products were present in striata and spinal cord but not in neurospheres. Type III forms gave a strong signal (500 bp) and a weak band at $440 \mathrm{bp}$ in neurospheres that decreased after adhesion. The most intense signal was seen in E14 striata and adult spinal cord. $C$, By RT-PCR, the RNAs encoding type III isoforms and made by undifferen- domain present in all NRG-1 isoforms (see Materials and Methods) (Fig. 1A). The adult spinal cord was used as positive control because the three types of NRG-1 isoforms are expressed in this region (Shinoda et al., 1997).

In adult spinal cord and E14 striatum, Ig-EGF primers detected three bands from 480 to $370 \mathrm{bp}$ that correspond to both type I and II isoforms either with or without a glycosylation domain (Fig. 1B). A weak signal was detected only at 480 bp in neurospheres (Fig. 1B). GGF2-EGF primers also detected three bands of type II isoforms (from 570 to $460 \mathrm{bp}$ ) in spinal cord and E14 striata, but there was no signal in neurospheres (Fig. 1B). In contrast, the type III isoform (CRD-EGF primers) gave an intense $500 \mathrm{bp}$ band and a weaker band at $440 \mathrm{bp}$ in spinal cord, striatum, and growing neurospheres with a decrease in intensity in differentiated spheres (Fig. 1B). Because the type III NRG-1 transcripts appear the most abundant, we designed other sets of primers that parse type III transcripts into secreted (Fig. 1 $\mathrm{A}, \mathrm{s}$ ) and transmembrane isoforms with a long and short cytoplasmic tail (Fig. 1, A, C, $a$ and $c$, respectively). Although the spinal cord and E14 striatum expressed these three type III isoforms, only the secreted form ( $s, 732$ bp band) and the transmembrane form with the long C-terminal domain ( $a, 1852 \mathrm{bp}$ band) were weakly detected in floating neurospheres (Fig. 1C). The 1852 bp product was cloned into a pCRII vector, and sequencing of seven clones revealed coding regions for type III transmembrane type $(a)$ isoforms, corresponding to $\alpha, \beta 1$, and $\beta 2 \mathrm{Nrg}-1$ variants. These variants are generated by alternative splicing in the region coding for the EGF-juxtamembrane portion (Fig. 1A). In our experiments, the EC domain of the $\beta$-2a type III variant that we cloned showed $91.5 \%$ identity with the EC domain of rat RASC9 sequence (Bermingham-McDonogh et al., 1997), 65.3\% identity with the chick $\beta$-2a NRG-CRD domain (Yang et al., 1998), and $81.3 \%$ identity with human soluble SMDF (Ho et al., 1995). Western blot analysis using antibodies directed against recombinant human SMDF (Fig. 1D, $45 \mathrm{kDa}$ band) revealed an $80 \mathrm{kDa}$ doublet corresponding to the MW of the transmembrane SMDF form in E14 striata, in Schwann cells (Rosenbaum et al., 1997), and in growing neurospheres (Fig. 1D). The soluble SMDF protein $(33-45 \mathrm{kDa})$ was not detected (Fig. 1D) but may have been lost during tissue extraction. The $80 \mathrm{kDa}$ product was also detected by polyclonal anti-Nrg-1 antibodies (HRG-C19) recognizing all Nrg-1 isoforms (data not shown). The intensity of bands detected by the anti-SMDF and anti-Nrg-1 antibodies was decreased in differentiated neurospheres, an observation that correlates with the RT-PCR data (Fig. $1 B, C$ ).

We then analyzed ErbB2, -3 , and -4 expression in E14 striata and growing and adherent neurospheres. Although we consistently detected both ErbB2 and ErbB4 by RT-PCR and Western analysis, an ErbB3 signal was not detected in these samples (Fig. $2 A, B)$. Positive controls include Schwann cells, which showed a

\section{$\leftarrow$}

tiated neurospheres were the soluble $(s)$ and the longest type $(a)$ transmembrane isoform. There was no signal for the isoform with the shortest cytoplasmic domain $(c)$. E14 striata and adult spinal cord expressed all three C-terminal isoforms. An additional band of an unidentified nature is present in adult spinal cord. $D$, Western blots of lysates of the E14 striata and neurospheres were compared with those of cultured neonatal mouse Schwann cells (Schwann). Antibodies directed against recombinant human SMDF identify in E14 striata, growing neurospheres, and Schwann cells a broad doublet of $\sim 80 \mathrm{kDa}$ that is undetectable in differentiated neurospheres. These antibodies recognized a preparation of purified soluble SMDF ( $r S M D F)$ at $45 \mathrm{kDa}$. 


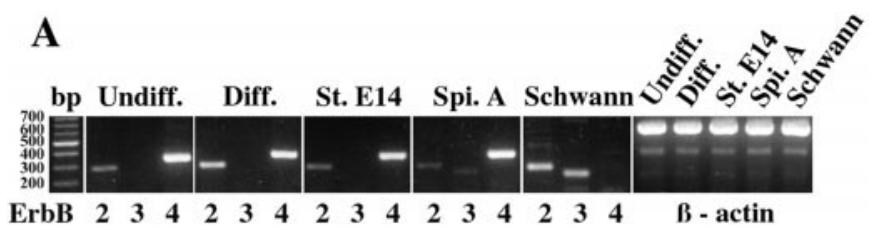

B

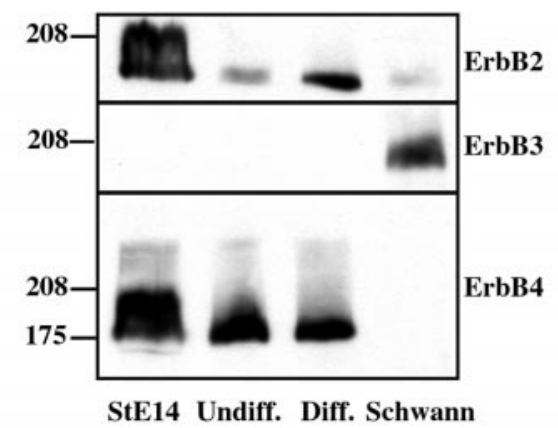

Figure 2. Expression of ErbB receptors in neurospheres before and after adhesion. $A$, RT-PCR analysis: RNA was extracted from four samples (denominated as in Fig. 1D) and from Schwann cells used as positive control. ErbB2 gave a signal in all samples. ErbB3 is absent in E14 striata and neurospheres but present in Schwann cells and adult spinal cord. ErbB4 is stronger than ErbB2 in all CNS samples and absent in Schwann cells. $B$, Western blot analysis was performed on extracts denominated as in Figure 1. Anti-ErbB2 antibodies detect a signal $\sim 180 \mathrm{kDa}$ in all samples. Anti-ErbB3 antibodies detect a band (160 kDa) only in cultured Schwann cell extracts but not in E14 striata or growing or adhering neurospheres. Anti-ErbB4 antibodies detect a $185 \mathrm{kDa}$ signal in all samples except Schwann cells.

strong ErbB3 signal using both techniques but no ErbB4 (Fig. 2A,B) (Grinspan et al., 1996; Vartanian et al., 1997).

Together, these results indicate that in E14 striatum and NPs derived from this region, the predominant Nrg-1 products consist of type III $80 \mathrm{kDa}$ transmembrane isoforms, which are downregulated in differentiating neurospheres. These Nrg-1 isoforms most likely signal through ErbB2-ErbB4 heterodimers or ErbB4 dimers expressed by NPs.

\section{Nrg-1 and ErbB receptors are coexpressed in neural precursors but levels of expression vary during differentiation}

To determine whether Nrg-1 isoforms and their receptors were expressed in the same or different NPs in vivo and in vitro, we used confocal fluorescence microscopy to examine cryosections of E14 striata and floating neurospheres double labeled with polyclonal antibodies to the mature form of Nrg-1 (HRG-C19 antibody) and to the ErbB2 or ErbB4 receptor. Merging of the two images taken in the fluorescein (ErbB receptor) and rhodamine (Nrg-1) mode showed that the majority of striatal cells (Fig. $3 A, B$ ) and NPs (Fig. $3 C, D$ ) coexpressed at least one of these two ErbB receptors and Nrg-1. ErbB2 and ErbB4 staining was detected both in the cell cytoplasm and at the membrane whereas Nrg-1 staining was mostly associated with the membrane (Fig. $3 A^{\prime}-D^{\prime}$ ). The orange color resulting from colocalization of Nrg-1 with ErbB2 or ErbB4 was mostly associated with the plasma membrane and appears more frequent in cells at the periphery of the neurosphere. These observations correlate well with the synthesis of a transmembrane
Nrg-1 isoform by NPs and suggest that signaling through the ErbB2 and ErbB4 receptors occurs mostly in an autocrine or paracrine way, or both.

We then examined whether expression of the Nrg-1 and ErbB receptors changes during differentiation of NPs into different CNS cell types after adhesion of neurospheres. Scattered, punctuate staining of Nrg-1, ErbB2, and ErbB4 was detected in both undifferentiated and differentiated cells of the sphere outgrowth (Figs. 3, 4). Quantitative analysis by confocal microscopy showed an important decrease of intensity of $\mathrm{Nrg}-1$ expression when compared with NPs in neurospheres (Fig. $3 K$ ). The comparison between single labeling for Nrg-1 and double labeling with cellspecific markers showed that Nrg-1 was mostly expressed by O4-positive preoligodendrocytes (Fig. $3 E, F$, white arrowheads) as well as by multiprocessed neuronal cells stained for the isoform III of tubulin in their cell bodies and processes (Fig. 3G,H, white arrowheads). In contrast, some mature astrocytes were negative for Nrg-1 (Fig. 3I,J, black arrowheads), whereas immature astrocytes showed more Nrg-1 staining (Fig. 3I,J, white arrowheads). Double labeling illustrated in Figure 4 showed that ErbB2 was expressed by the majority of differentiated cells (Fig. 4A,C,E, white arrowheads), although some oligodendrocytes, neurons, and astrocytes were negative for ErbB4 (Fig. 4B,D,F, black arrowheads). Thus the majority of differentiated cells still express Nrg-1 and its two receptors.

\section{Nrg-1 controls the growth and survival of neurospheres}

To investigate the effects of Nrg-1 on NPs, we first tested whether addition of GGF2 (at 50 or $200 \mathrm{ng} / \mathrm{ml}$ ) to the medium of growing neurospheres would increase their rate of formation or their size, but we observed no significant effect compared with untreated spheres after $6 \mathrm{~d}$ of growth (data not shown). We also investigated whether ErbB2 and ErbB4 receptors were phosphorylated after addition of GGF2, using immunoprecipitation followed by phosphotyrosine antibody labeling (Vartanian et al., 1997). A weak signal for phosphorylated ErbB4 was found in two experiments on neurospheres, but no definite phosphorylated ErbB2 band was detected (data not shown).

Given the expression of Nrg-1 isoforms and ErbB receptors in neurospheres (Figs. 1-4), we reasoned that endogenous Nrg-1 had probably saturated the receptors at $6 \mathrm{~d}$. We therefore used a different assay to test GGF2 effects in conditions of minimal endogenous Nrg-1. Freshly dissociated striatal NPs were seeded with different concentrations of GGF2, and their growth was measured after only $2 \mathrm{~d}$ by MTT assay. In this condition, GGF2 addition produced a small but significant increase in cell growth (1.5-fold with $2 \mathrm{ng} / \mathrm{ml}$ of GGF2, twofold with $20 \mathrm{ng} / \mathrm{ml}$ of GGF2, and 1.8-fold with $200 \mathrm{ng} / \mathrm{ml}$ of GGF2 in comparison with control condition). These results suggest a role of $\mathrm{Nrg}-1$ in the early growth of NPs. Therefore, we engineered a cDNA encoding sErbB3, the amino-terminal domain of which specifically binds to Nrg-1 ligands, which we purified from transfected $\mathrm{CHO}$ cells. Although soluble ErbB4 has been used before as an Nrg-1 inhibitor (Pinkas-Kramarski et al., 1997; Vartanian et al., 1999), more recent studies have revealed that at least seven ligands bind to ErbB4 (Nrg-1, -2, -3, and -4, betacellulin, epiregulin, and heparinbinding EGF) (Olayioye et al., 2000). Thus we chose sErbB3 as a specific inhibitor of Nrg-1 isoforms assuming that it would bind to the type III isoforms made by neurospheres. As a control for this inhibitor, we prepared a soluble form of the $\beta$ subunit of the glycine receptor (sGlyr), which does not bind glycine (Betz et al., 


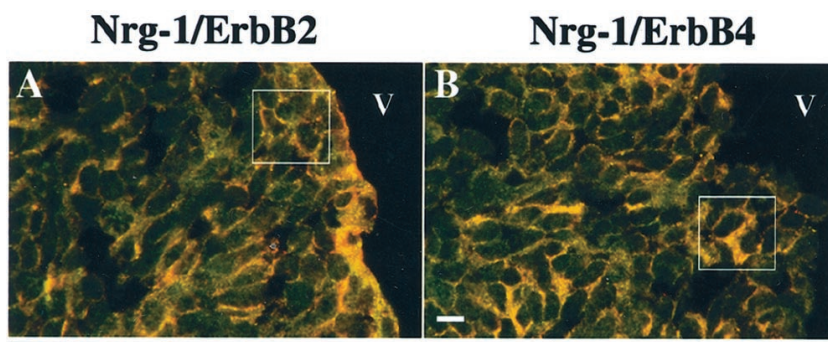

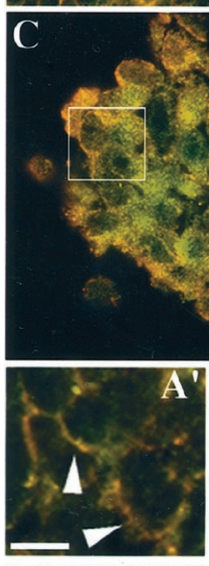
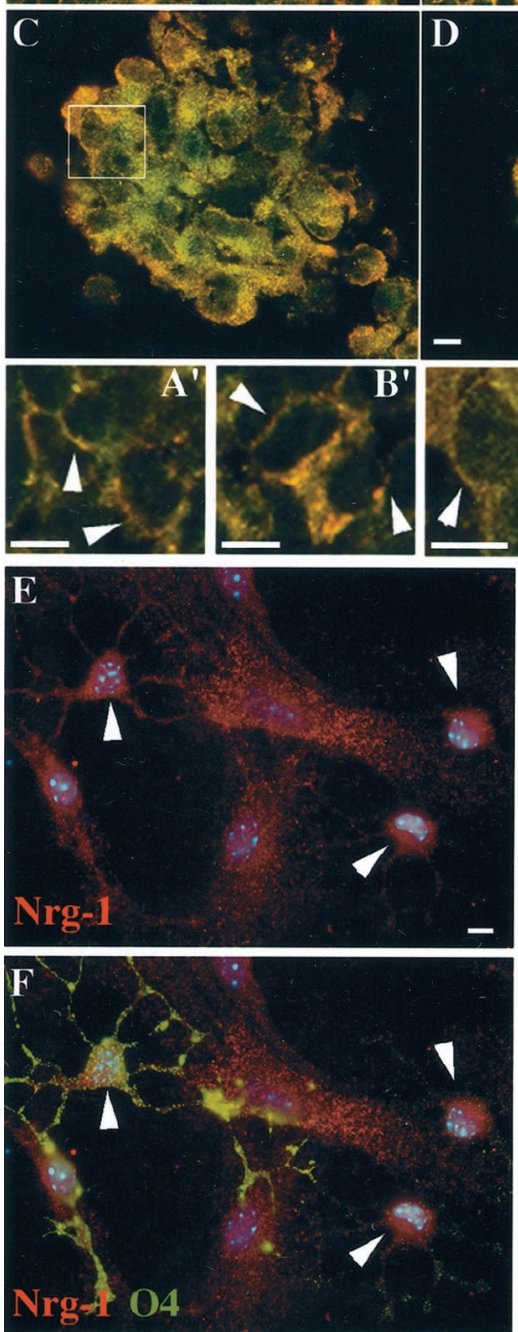

D

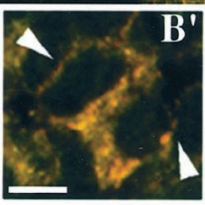

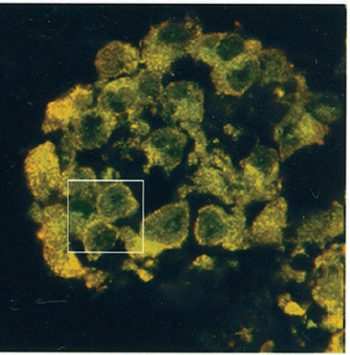
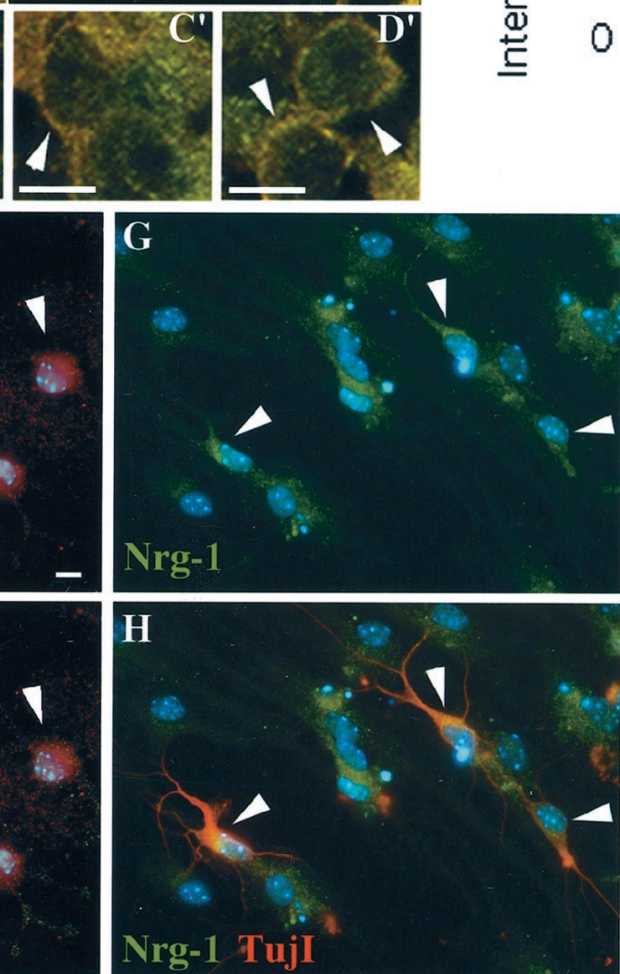

$\mathbf{K}$
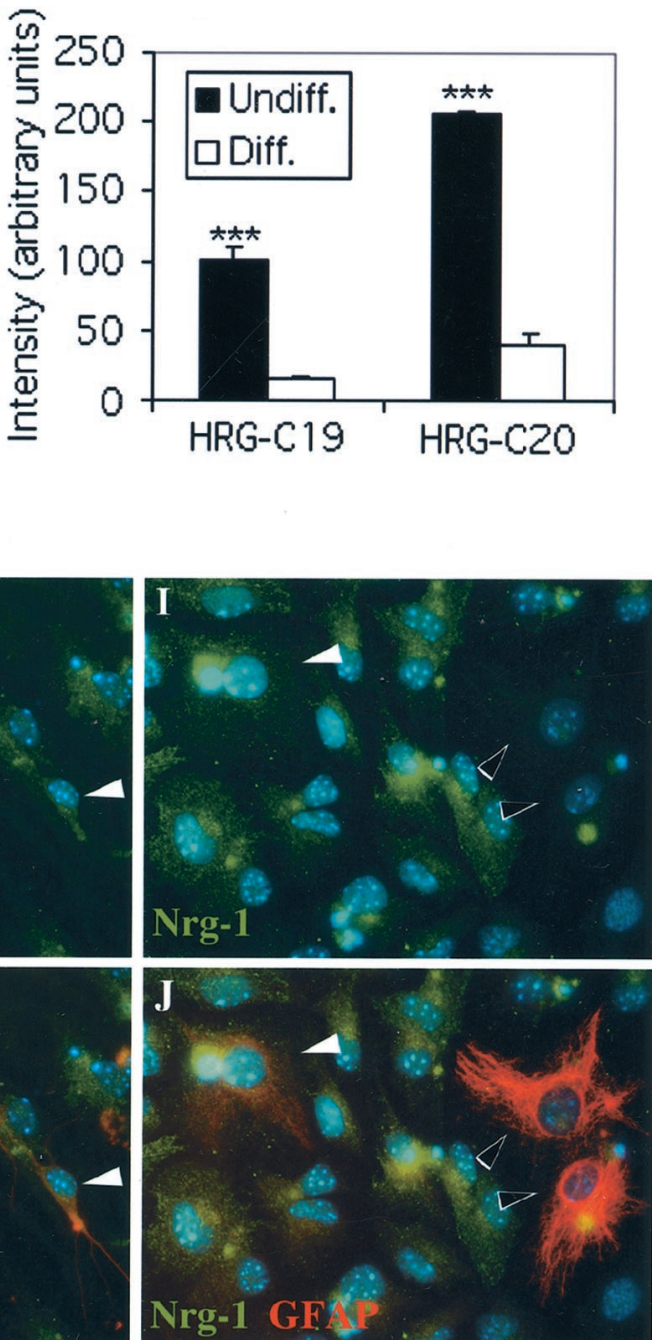

Figure 3. Nrg-1, ErbB2, and ErbB4 expression in E14 striatum and neurospheres. $A-D$, Confocal imaging was done after double immunolabeling with goat antibody to human Nrg-1 (HRG-C19, rhodamine in $A-D$ ) and a rabbit antibody against human ErbB2 (fluorescein; $A, C$ ) or ErbB4 receptor (fluorescein; $B, D)$. The merged images show the coexpression of each ErbB receptor with Nrg-1 in orange in striatum $(A, B)$ and neurospheres $(C, D)$. $A$ ' $-D$ ', The strong membrane signal of individual cells (arrows) is shown in the close-up corresponding to the frames indicated in $A-D$. $V$, Ventricule. $E-J$, Expression of Nrg-1 in differentiated cells in the outgrowth from neurospheres. Note that Nrg-1 is in red in $E$ and $F$ and in green in $G-J$ and that nuclei are stained blue by DAPI. $E, F$, Six days after sphere adhesion, many cells in the outgrowth are preoligodendrocytes labeled with O4 antibody ( green). Single $(E)$ and double $(F)$ label show scattered dots of $\mathrm{Nrg}-1$ (red, HRG-C20 antibody) colocalized with $\mathrm{O} 4$ staining. White arrows in $F$ indicate three double-labeled cells: one is strongly O4 positive (left arrow), whereas the two cells at right arrows are weakly stained with $\mathrm{O} 4$ antibodies. Nrg-1 is also detected in a double-labeled spindle-shaped OP in the left corner of $F$. $G, H$, Neuronal cells stained with TujI antibody (red) express Nrg-1 (green, HRG-C20 antibody) as indicated by the orange label in three cells indicated by white arrows in $H$. $I, J$, A cell with a weak GFAP staining (red) shows a strong signal for Nrg-1 (green, HRG-C20 antibody) resulting in orange labeling of this immature astrocyte (J, white arrow). In contrast, strongly GFAP-positive astrocytes (in red) are not stained by Nrg-1 antibody (compare $I$ and $J$ at the two black arrows). Scale bars, $10 \mu \mathrm{m}$. $K$, Quantitative analysis of confocal images of cells stained with two different antibodies to Nrg-1 proteins (HRG-C19 and $H R G$-C20). Fluorescence intensity of Nrg-1 labeling decreased in differentiated cells of adherent neurospheres after $6 \mathrm{~d}$ when compared with undifferentiated NPs within neurospheres.

1999) and therefore could not interfere with a putative glycine signaling in neurospheres. The purified sErbB3 and sGlyr had a MW of 80 and $75 \mathrm{kDa}$, respectively, as shown by Western blot analysis (Fig. $5 A$ ). The biological activity of sErbB3 was analyzed using a tritiated thymidine incorporation assay on rat Schwann cells. We first tested whether sErbB3 had an effect on cell proliferation of rat Schwann cells grown without GGF2 in the presence of increasing doses of sErbB3 and found no significant changes compared with untreated cultures even at the highest dose (Table 2). We then assayed whether rat Schwann cell mitosis induced by 
ErbB2
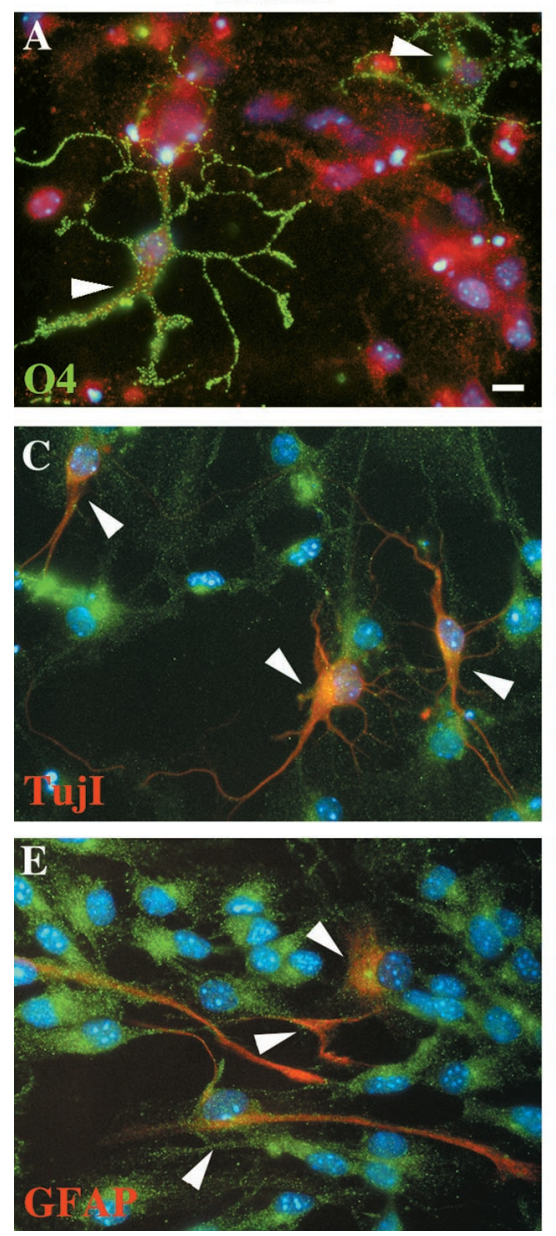

ErbB4
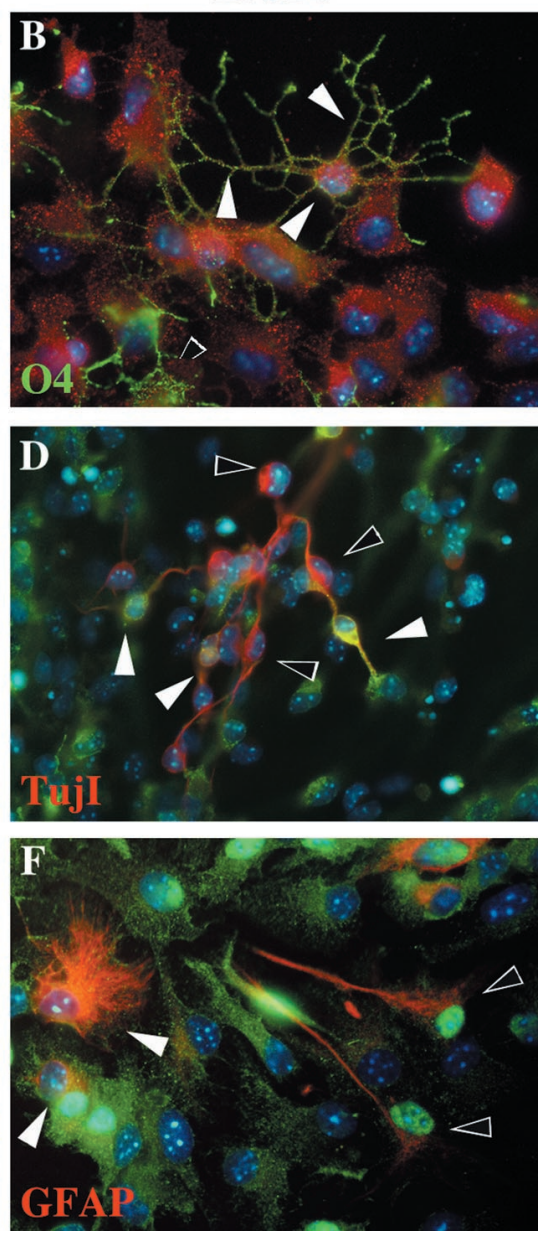

Figure 4. ErbB expression in differentiated cells. Double labeling with nuclei stained blue by DAPI. Note that ErbB receptors are in red in $A$ and $B$ and in green in $C-F . A, B$, ErbB2 $(A)$ and ErbB4 $(B)($ red $)$ are detected in both the cell body and processes of preoligodendrocytes producing an orange staining of the cytoplasm around the blue nucleus (white arrowheads). In $B$, note one oligodendrocyte strongly stained by $\mathrm{O} 4$ (green), which is ErbB4 negative (black arrowhead). C, D, Neurons labeled with TujI (red) and ErbB2 (green) show orange label in their cell bodies and processes $(C$, white arrowheads). In contrast, only a few TujI-positive cells express ErbB4 (orange cells in $D$ at white arrowheads). Other bipolar neuronal cells are mostly red, showing weak or no labeling for ErbB4 (D, black arrowheads). E, F, All astrocytes coexpress GFAP (red) and ErbB2 (green), resulting in orange staining (white arrowheads), but some do not express ErbB4 (red-labeled astrocytes at black arrowheads in $F$ ). Scale bar, $10 \mu \mathrm{m}$.
$20 \mathrm{ng} / \mathrm{ml}$ of GGF2 was inhibited by increasing concentrations of sErbB3. The soluble receptor used at $250 \mathrm{ng} / \mathrm{ml}$ inhibited $50 \%$ of the 15 -fold increase in proliferation induced by GGF2 (Table 2). Finally, Schwann cell survival was measured in the presence of increasing doses of sErbB3 (up to $1000 \mathrm{ng} / \mathrm{ml}$ ) by a calcein-AM fluorescent assay (Gatti et al., 1998), which did not reveal any significant cell death compared with untreated Schwann cells (data not shown).

To evaluate the effects of this Nrg-1 inhibitor on neurosphere growth, we added $0.1 \mu \mathrm{g} / \mathrm{ml}$ to $1 \mu \mathrm{g} / \mathrm{ml}$ of $\mathrm{sErbB} 3$ or $1 \mu \mathrm{g} / \mathrm{ml}$ of sGlyr at the time of seeding of the NPs. sErbB3 decreased the neurosphere size but did not inhibit neurosphere formation (Fig. $5 B)$. After $6 \mathrm{~d}$ of growth in suspension, there was a significant and dose-dependent reduction in both the size and number of neurospheres growing in the presence of sErbB3, whereas addition of sGlyr had no effect compared with neurospheres grown in control medium (Fig. 5C,D). To determine whether sErbB3 inhibited cell proliferation or survival, or both, we first evaluated DNA synthesis by adding BrdU during the last $24 \mathrm{hr}$ to neurospheres cultured for 2 or $6 \mathrm{~d}$ in the presence or absence of $\operatorname{sErbB} 3(0.5 \mu \mathrm{g} / \mathrm{ml})$ and sGlyr $(0.5 \mu \mathrm{g} / \mathrm{ml})$ (Fig. $5 E)$. The same experimental design and time points were used to assay apoptosis by the TUNEL method (Fig. $5 F$ ). sErbB3 significantly decreased cell proliferation and increased the percentage of apoptotic cells after 2 or $6 \mathrm{~d}$ in culture (Fig. $5 E, F$ ). However, these effects varied with time. At $2 \mathrm{~d}$, sErbB3 decreased the proliferative index 4.5-fold (from $27 \pm$ $1 \%$ in control condition to $6 \pm 3 \%$ ), whereas at $6 \mathrm{~d}$ the decrease was merely $13 \%$ (from $81 \pm 2 \%$ to $68 \pm 2 \%$ ) (Fig. $5 E$ ), suggesting either a low efficiency of sErbB3 blocking after $6 \mathrm{~d}$ or that other mitogens were stimulating proliferation at this stage. In contrast, sErbB3 treatment increased NP apoptosis two to three times at both time points, whereas there was no significant change in the apoptosis index between 2 and $6 \mathrm{~d}$ in control and sGlyr-treated cultures (Fig. $5 F$ ). These experiments demonstrate that endogenous Nrg-1 enhances the growth and survival of NPs in neurospheres.

\section{sErbB3 treatment of neurospheres enhances oligodendrocyte generation after adhesion}

To investigate whether sErbB3 influences cell differentiation after adhesion of neurospheres, we analyzed by immunocytochemistry the different CNS cell types in the outgrowth of control or sErbB3-treated neurospheres (as described above). In one group, the inhibitor was washed out before neurosphere adhesion, whereas it was added for $2 \mathrm{~d}$ in the other group (Fig. 6). The total number of cells that had migrated out of each neurosphere was determined for each condition (Fig. 6A), and the respective ratios of oligodendrocytes, neurons, and astrocytes to this total cell number were determined (Fig. 6B). As predicted from the results of the experiments on neurospheres (Fig. 5), neurosphere treatment with sErbB3 before adhesion significantly decreased the total number of cells migrating out of neurospheres, whereas sErbB3 added after adhesion had no such effect (Fig. 6A). Most of the outgrowth cells were still undifferentiated NPs at $2 \mathrm{~d}$. 


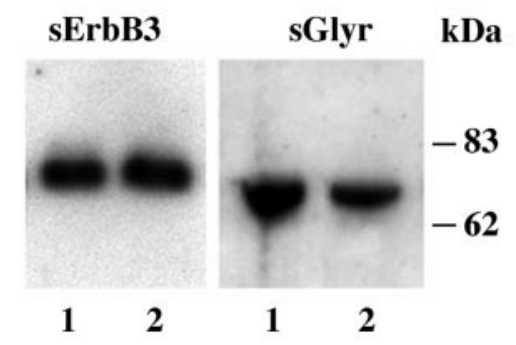

Figure 5. Effect of soluble ErbB3 on neurosphere formation and growth. $A$, Purification of soluble ErbB3 (sErbB3) and $\beta$ subunit of glycine receptor ( $s G l y r)$. Western blot analysis of total extract of sErbB3- and sGlyr-transfected CHO cells (lane 1) or of purified protein (lane 2). Detection with an anti-myc antibody that recognized Myc tag present on sErbB3 and sGlyr constructs revealed a single band of $\sim 80$ and $75 \mathrm{kDa}$, respectively, for sErbB3 and sGlyr. $B$, Phasecontrast micrographs show the reduction in size of neurospheres cultured for $6 \mathrm{~d}$ in the presence of $0.5 \mu \mathrm{g} / \mathrm{ml}$ of sErbB3 compared with untreated control cultures or neurospheres grown in the presence of $0.5 \mu \mathrm{g} / \mathrm{ml}$ of sGlyr. Scale bar, $100 \mu \mathrm{m}$. $C, D$, The neurospheres were grown for $6 \mathrm{~d}$ in the presence of different concentrations of sErbB3 or of 1 $\mu \mathrm{g} / \mathrm{ml}$ of sGlyr. The diameter of 50 spheres $(C)$ and the total number of spheres $(D)$ for each condition were determined. Treatment with sErbB3 decreased the size $(C)$ and number $(D)$ of neurospheres in a dose-dependent manner. Each bar represents the mean \pm SEM of triplicate experiments done three times. $E, F$, The neurospheres were grown for $2 \mathrm{~d}$ in the presence or absence of $0.5 \mu \mathrm{g} / \mathrm{ml}$ of sErbB3 or of sGlyr. BrdU was added to the culture $24 \mathrm{hr}$ before staining $(E)$. Spheres were plated onto poly-D-lysine/fibronectin-coated coverslips for $30 \mathrm{~min}$ at $37^{\circ} \mathrm{C}$, then fixed and processed for BrdU $(E)$ or TUNEL $(F)$ staining and counterstained with DAPI to visualize all nuclei within the spheres. The ratio of BrdU-positive cells $(E)$ and TUNEL-positive cells $(F)$ to total cells was determined within at least 30 spheres. Each bar represents the mean \pm SEM of three experiments with triplicates. Treatment with sErbB3 decreased the proliferative rate of neurospheres, but more so at $2 \mathrm{~d}$ than $6 \mathrm{~d}(E)$, and increased cell apoptosis at both time points $(F)$. Student $t$ test: ${ }^{* * *} p<0.01$.
A

B

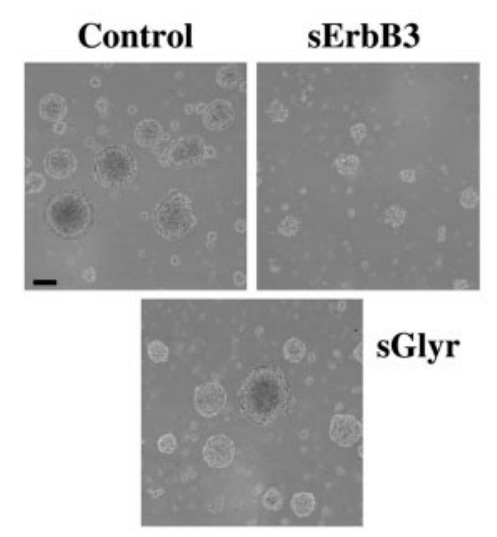

D
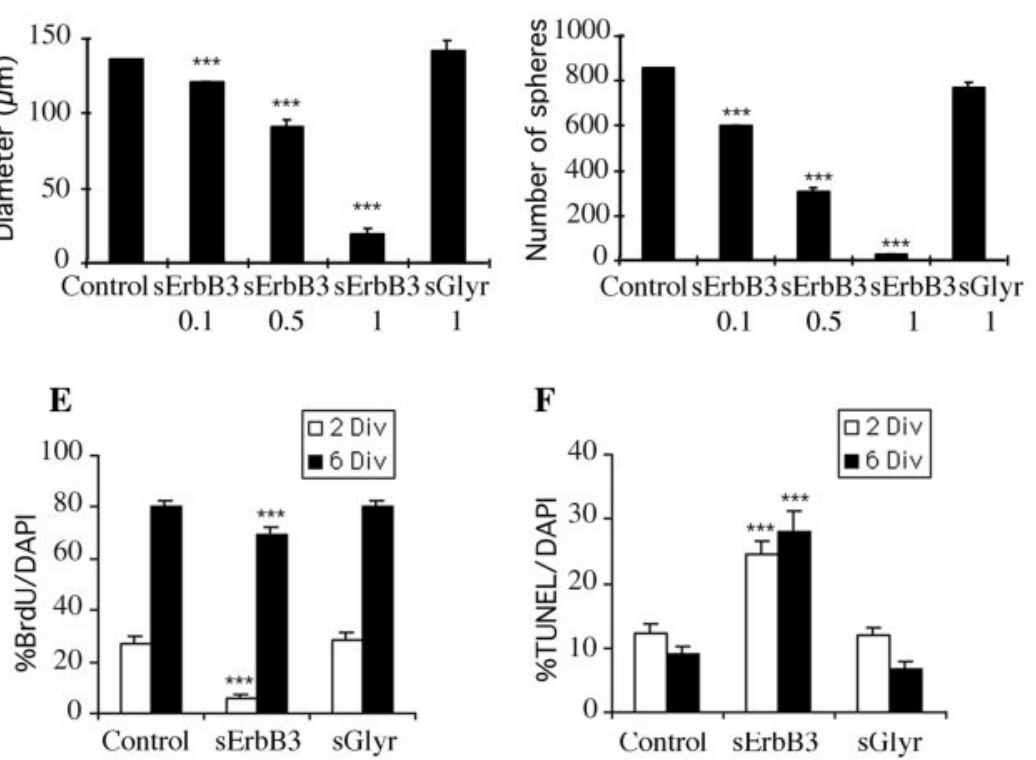

F

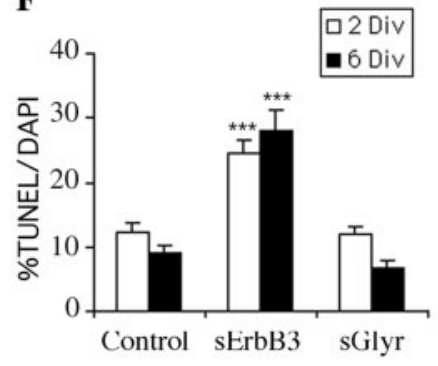

Table 2. sErbB3 biological activity on rat Schwann cells

Effect on mitosis

\begin{tabular}{ccccc}
\cline { 1 - 2 } $\begin{array}{c}\text { sErbB3 dose } \\
\text { in } \mathrm{ng} / \mathrm{ml}\end{array}$ & $\begin{array}{l}\mathrm{H}^{3} \text { thymidine } \\
\text { incorporation }\end{array}$ & & $\begin{array}{l}\text { sErbB3 dose } \\
\text { in } \mathrm{ng} / \mathrm{ml}\end{array}$ & $\begin{array}{l}\mathrm{H}^{3} \text { thymidine } \\
\text { incorporation }\end{array}$ \\
\hline 0 & $2130 \pm 310$ & & 0 & $35877 \pm 1257$ \\
100 & $2370 \pm 245$ & & 40 & $33718 \pm 1932$ \\
500 & $2733 \pm 336$ & & 85 & $31465 \pm 1561$ \\
1000 & $2778 \pm 890$ & & 170 & $20042 \pm 2119$ \\
2000 & $2376 \pm 258$ & & 250 & $16050 \pm 870$
\end{tabular}

Schwann cell cultures were exposed to various concentrations of sErbB3 alone (Effect on mitosis) or in the presence of GGF2 at $20 \mathrm{ng} / \mathrm{ml}$ (Inhibition of GGF2induced mitosis). The tritiated thymidine incorporation was performed between 24 and $48 \mathrm{hr}$ and is expressed in $\mathrm{dpm}$ per $\mathrm{mg}$ of protein per sample \pm SEM of triplicate cultures.

Among the differentiated cells, surprisingly, the ratio of O4positive preoligodendrocytes to total cells was three times greater after adhesion of sErbB3-treated neurospheres $(15 \pm 3 \%)$ than of control $(5 \pm 1 \%)$ or sGlyr-treated neurospheres $(6 \pm 2 \%)$. This effect was specific for preoligodendrocytes because the ratio of GFAP-positive astrocytes or TujI-positive neuronal cells was not increased. Addition of sErbB3 after adhesion did not increase the percentage of preoligodendrocytes $(7 \pm 2 \%)$ (Fig. $6 B)$. These results indicate that $\mathrm{sErbB} 3$ treatment of growing neurospheres can selectively prime the precursors for oligodendrocyte differentiation. The preferential recruitment of these cells from the undifferentiated NPs could also indicate an accelerated process of differentiation in the presence of the Nrg-1 inhibitor.

The effect of the soluble receptor was compared with that of GGF2 before and after adhesion. GGF2 treatment increased the number of cells in the outgrowth and moderately decreased the percentage of preoligodendrocytes (from $5 \pm 1$ to $3 \pm 0.3 \%$ ) (Fig. $6 A, B)$. In addition, GGF2 increased the percentage of GFAPpositive cells from $0.5 \pm 0.2$ to $4 \pm 0.5 \%$ as described previously (Pinkas-Kramarski et al., 1994), whereas the percentage of neuronal progenitors was not significantly changed (Fig. 6B). These results indicate that recombinant Nrg-1 to some degree favors development of astrocytes over that of oligodendrocytes from the NP pool.

Because soluble ErbB receptor emerged as a strong inducer of oligodendrocyte development, we also studied the effect of sErbB3 pretreatment of growing neurospheres on expression of GC and MBP, two markers of postmitotic oligodendrocytes. Such sErbB3 pretreatment resulted in a significant increase in the percentage of GC-positive cells after adhesion (from $6 \pm 2 \%$ in control to $12 \pm$ 
A

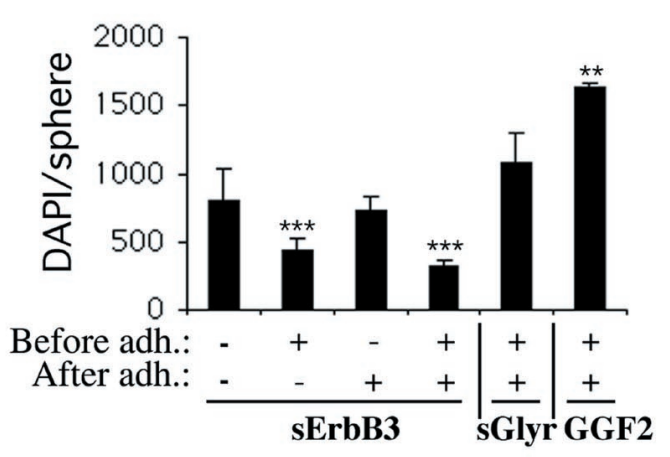

B

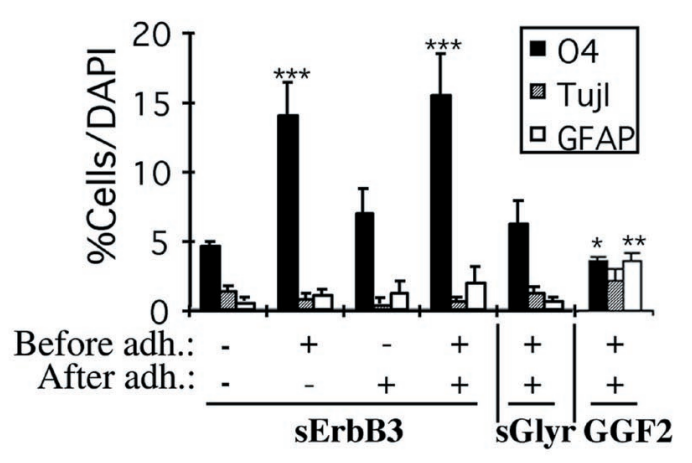

C

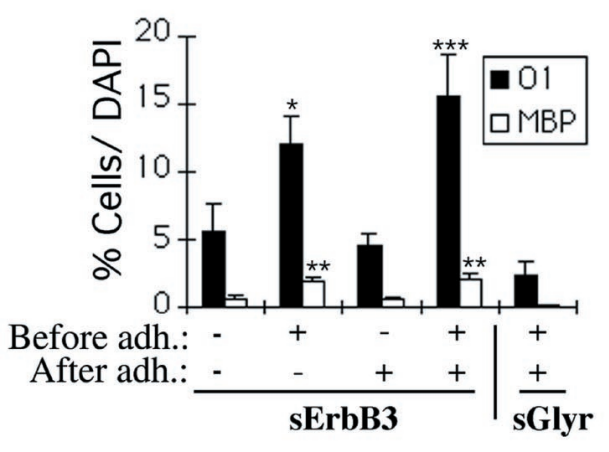

D
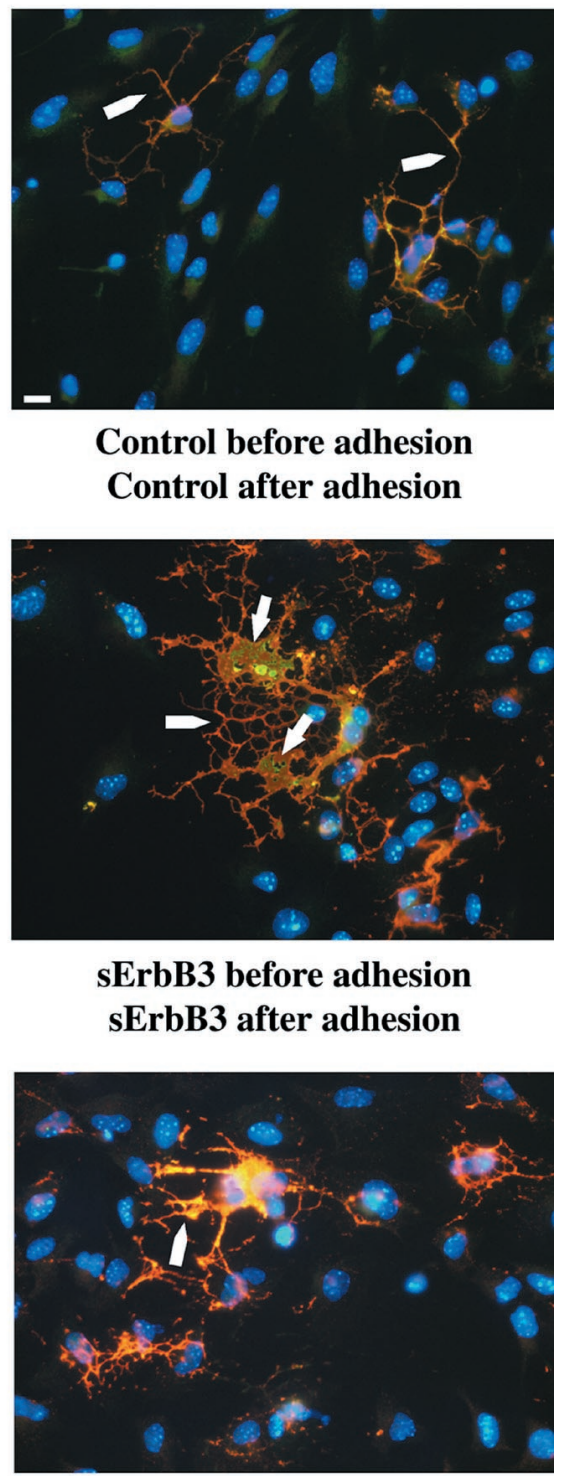

sGlyr before adhesion sGlyr after adhesion
Figure 6. Effect of soluble ErbB3 and GGF2 on neurosphere differentiation. The neurospheres were grown for $6 \mathrm{~d}$ in the presence of $0.5 \mu \mathrm{g} / \mathrm{ml}$ of sErbB3 or sGlyr or in the presence of $100 \mathrm{ng} / \mathrm{ml}$ of GGF2 and then adhered for $2 \mathrm{~d}$ to allow differentiation in the presence or absence of these soluble proteins. Cultures were either triple labeled with $\mathrm{O} 4$ (for preoligodendrocytes), TujI (for neuronal cells), or GFAP (for astrocytes) antibodies $(B)$ or double labeled with $\mathrm{O} 1$ and MBP antibodies (for oligodendrocytes; $C, D)$ and counterstained with DAPI $(A-D)$. The ratio of each cell type to the total number of cells in the outgrowth was determined. $A$, The total number of DAPI-positive cells that migrated out of each adherent sphere decreased when the growing spheres were first cultured in the presence of sErbB3. After adhesion, sErbB3 shows no effect on the number of migrating cells. In contrast, addition of GGF2 increased the total number of cells. $B$, The ratio of O4-positive cells increased by approximately three times in the presence of sErbB3, whereas the ratio of neuronal cells and astrocytes stayed the same. The increase in the oligodendrocyte ratio was not seen if sErbB3 was added only after neurosphere adhesion $(B, C)$. In the presence of GGF2, the percentage of oligodendrocytes decreased and astrocytes significantly increased, whereas the percentage of neuronal TuJI-positive cells was not significantly changed. $C$, The percentage of either O1- or MBP-positive cells in the outgrowth had also increased at $2 \mathrm{~d}$ after adhesion of neurospheres pretreated with sErbB3. This effect was not observed with neurospheres treated with sErbB3 only after adhesion. Each bar represents the mean \pm SEM of three spheres from triplicate experiments done three times. Student $t$ test: * $p<0.05 ;{ }^{* *} p<0.02 ;{ }^{* * *} p<0.01 . D$, After sErbB3 treatment, cells coexpressing MBP (green dots at arrowheads) in processes of galactocerebroside-positive oligodendrocytes (O1 antibody in red) showed an increased complexity of the processes (arrow) compared with oligodendrocytes in control and sGlyr-treated cultures. Scale bar, $10 \mu \mathrm{m}$.
$2 \%$ ) and a doubling of the percentage of MBP-positive cells (from $1 \pm 0.3 \%$ in control to $2 \pm 0.4 \%$ ) (Fig. $6 C$ ). Interestingly, when sErbB3 treatment was maintained throughout neurosphere growth and differentiation, the percentage of $\mathrm{GC}$-positive cells (Fig. 6C) further increased from $12 \pm 2$ to $16 \pm 3 \%$, and the complexity of oligodendrocyte processes was increased when compared with control (Fig. 6D). As observed with the O4 labeling, addition of sErbB3 exclusively after adhesion did not significantly modify the percentage of GC- and MBP-positive cells versus controls (Fig. $6 C$ ). Together these results demonstrate that sErbB3 favored oligodendrocyte development and may accelerate their differentiation.

\section{DISCUSSION}

Our study demonstrates that NPs within the embryonic striatum and grown in neurospheres synthesize multiple NRG-1 transcripts and proteins as well as the ErbB2 and ErbB4 receptors. Although both secreted and transmembrane type III NRG-1 isoforms were identified by RT-PCR in growing neurospheres, only one dominant Nrg-1, the transmembrane SMDF/CRDNRG isoform, was demonstrated by Western analysis. ErbB receptors and Nrg-1 are coexpressed in NPs, and treatment with sErbB3 (which binds Nrg-1 ligands) decreases proliferation and increases apoptosis of these precursors, resulting in a significant reduction in neurosphere size and number. Thus Nrg-1 made by striatal neural precursors promotes their growth via autocrine or paracrine signaling, or both. Furthermore, the ability of GGF2 to enhance only the initial stage of neurosphere growth in lowdensity cultures suggests that the level of Nrg-1 bioactivity was rapidly saturating in this culture system. After adhesion, GGF2 treatment favored astrocyte rather than oligodendrocyte differentiation (Pinkas-Kramarski et al., 1994; Canoll et al., 1996, 1999). In contrast, sErbB3 pretreatment of growing neurospheres acts as an inducer or accelerator of oligodendrocyte generation with no apparent effects on neuronal and astrocyte lineages. These effects were specific because an unrelated soluble receptor 


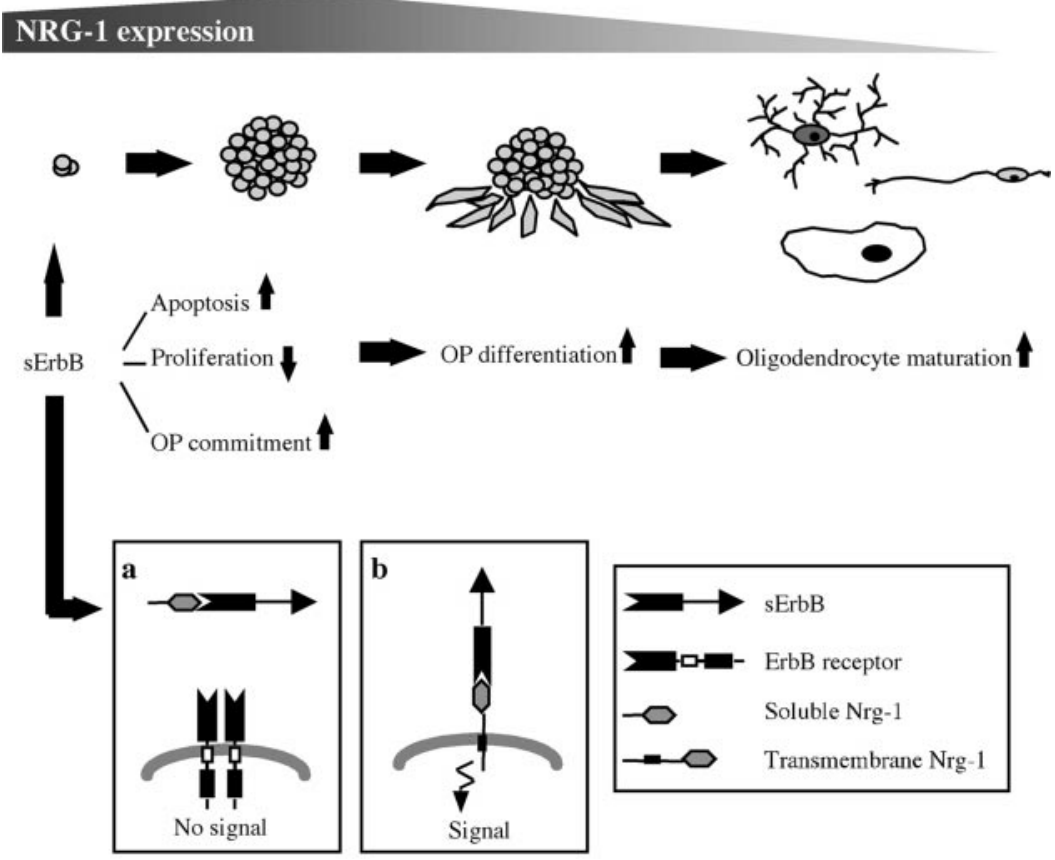

Figure 7. Diagram of the hypothetical mechanisms of action of Nrg-1 signaling in NPs and oligodendrocyte differentiation. NPs, growing in neurospheres, strongly expressed Nrg-1. After adhesion, NPs migrated out of neurospheres and progressively differentiated into astrocytes, neurons, and oligodendrocytes, all weakly expressing Nrg-1. Addition of sErB (in this study, sErbB3) during neurosphere formation increased NP apoptosis, decreased NP proliferation rate, and increased oligodendrocyte differentiation, suggesting an increase in OP selection or commitment, or both. The framed panels show two different interpretations of these data. In $a$, sErbB blocks endogenous Nrg-1, soluble or transmembrane, decreasing its mitotic and survival effect on NPs; in $b$, sErbB binds to transmembrane Nrg-1 to trigger an intracellular signal of an unknown nature.

had no influence on neurosphere growth and differentiation. These observations lead us to suggest that SMDF/CRD-NRG signaling and soluble ErbB receptors may both contribute to oligodendrocyte development from neural stem cells.

Previous studies have shown that FGF2 and EGF enhance neural stem cell growth in vivo and in vitro (for review, see Brüstle and Dubois-Dalcq, 2001). Nrg-1 can now be added to the factors promoting the mitosis and survival of NPs isolated from germinative zones such as the embryonic striatum. EGF responsiveness of such striatal precursors is promoted in vitro by a 2 d FGF2 treatment, indicating that FGF2 may induce the EGF receptor, ErbB1, in these cells (Ciccolini and Svendsen, 1998). In keeping with this, rat neurospheres express ErbB1 transcripts (B. Rogister, unpublished observations). Here we described that two Nrg-1 receptors, ErbB2 and ErbB4, were already expressed in the E14 striatum from which NPs were derived. This is in keeping with the observation that ErbB4 is expressed in the rat E12 and adult ventricular and subventricular zones (Eagleson et al., 1998; Steiner et al., 1999). Addition of EGF was required to initiate NP growth in neurospheres, whereas endogenous Nrg-1 supported mitosis and expansion of sphere size in the first days in vitro. ErbB2, which does not bind Nrg-1, is the preferred dimerization partner for all other ErbB receptors, and these dimers show increased ligand affinities and prolonged signaling activation (Olayioye et al., 2000). It is therefore possible that ErbB2 expressed in our neurospheres formed heterodimers not only with ErbB4 but also with ErbB1, the EGF receptor. The absence of ErbB3 transcripts and protein in mouse E14 striatum and neurospheres correlates well with the absence of any in situ hybridization signals reported in these regions at this age (Meyer et al., 1997). ErbB3 is transiently detected in rat E12 cortical progenitors in vitro and at E16 in the germinative zone around the third ventricle (Eagleson et al., 1998; Kornblum et al., 2000). Thus our observations on neurospheres suggest an important physiological role of autocrine or paracrine signaling involving Nrg-1 and
ErbB2-ErbB4 or ErbB4-ErbB4 dimers in NP development in the forebrain.

Our study also provides evidence that type III transmembrane SMDF/CRD is the Nrg-1 isoform specifically involved in promoting NP growth in neurospheres. Although the RT-PCR signal detected the secreted and long transmembrane isoform, Western blot analysis revealed only the transmembrane type III SMDF/ CRD in the striatum and in differentiated neurospheres. This does not exclude the possibility that the soluble protein was made but not detected in our experimental conditions. Although type I or II NRG-1 transcripts were detected in E14 striatum (Meyer et al., 1997) (our RT-PCR data), no type II signal and no GGF2 isoform were detected in neurospheres by Western blot or ELISA on the medium (data not shown). Type III SMDF/CRD isoforms may be less essential during migration and differentiation of NPs because the intensity of RT-PCR, fluorescence, and Western blot signals significantly decreased after neurosphere adhesion. It is possible that another Nrg-1 isoform influences cell differentiation at that time. SMDF/CRD Nrg-1 regulates synapse maintenance and function at the neuromuscular junction as well as Schwann cell development (Meyer et al., 1997; Wolpowitz et al., 2000). Indeed, mice deficient in this type III Nrg-1 isoform showed poor Schwann cell survival, whereas type I and II NRG-1 knock-out mice, in which the Ig domain was disrupted but the SMDF/CRD domain was preserved, had normal Schwann cell precursors (Meyer et al., 1997; Wolpowitz et al., 2000). Our results now suggest that this pleiotrophic type III Nrg-1 isoform can also promote NP growth.

The strong and specific effect of sErbB3 treatment on oligodendrocyte generation from NPs is of particular interest. When this Nrg-1 inhibitor was added during sphere growth for $6 \mathrm{~d}$, the relative oligodendrocyte population in the outgrowth had tripled compared with control, whereas the proportion of neuronal and astrocytic cells in the outgrowth remained unchanged. There are several possible interpretations of these findings (Fig. 7). The 
simplest one is that Nrg-1 acts not only as mitogen for NPs but also inhibits differentiation of early OPs (Canoll et al., 1996, 1999). When Nrg-1 is downregulated at the time of differentiation or inhibited by sErbB3, OPs would exit the cell cycle and differentiate rapidly into oligodendrocytes. Another possibility is that the overall reduction of NP numbers attributable to sErb3 treatment could result in a preferential decrease in neuronal progenitors or astrocytes, or both. Because Nrg-1 promotes embryonic retinal neuron survival and differentiation (BerminghamMcDonogh et al., 1996) and prevents apoptosis and accelerates the maturation of astrocytes (Pinkas-Kramarski et al., 1994), sErb3 could cause a decrease in these two populations. However Nrg-1 is also a potent survival factor for differentiated oligodendrocytes (Fernandez et al. 2000; Flores et al. 2000), and therefore sErbB should equally decrease their number, but the reverse is observed here. Because sErbB3 acts at an early stage during neurosphere growth, it may positively select for precursors precommitted to an oligodendrocyte fate. These precursors would then go on to differentiate into oligodendrocytes after adhesion, a process that may be favored by the decrease in Nrg-1 at that time. Finally, PDGF, which is made in neurospheres (Rogister, unpublished observations) and is playing an important role in oligodendrocyte development (Calver et al., 1998), may compensate for the decrease in functional Nrg-1 and preferentially stimulate OP to divide within the sphere, resulting in increased generation of oligodendrocytes. The mechanisms considered here are in keeping with the importance of short-range membranebound regulatory signals in stem cell differentiation (Tsai and McKay, 2000).

What then is the physiological stimulus of differentiation of oligodendrocytes in vivo? Interestingly, two isoforms of the ErbB4 receptor have been described that differ in the juxtamembrane portion of the extracellular domain JMa [(23 amino acid (aa)], which is cleavable, and JMb (13 aa), which is noncleavable (Elenius et al., 1997; Rio et al., 2000). These two forms of ErbB4 receptors are expressed in a tissue-specific manner and have been detected in cerebellum (Elenius et al., 1997). Proteolytic cleavage in the JMa region is induced by TACE (TNF- $\alpha$ converting enzyme), a member of the metalloprotease desintegrin family (ADAM) (Rio et al., 2000), the differential expression of which in the germinative zone and neural precursors is presently unknown. Moreover, an EGF domain peptide of a $\beta 1 \mathrm{Nrg}-1$ isoform can induce this ErbB4 cleavage (Zhou and Carpenter, 2001). The ability of ErbB4 to be cleaved leads us to propose that, in vivo, soluble ErbB4 could stop mitosis of oligodendrocyte progenitors triggered by Nrg-1, allowing their differentiation, as does sErbB3 in our in vitro model. Soluble ErbB4 could act on oligodendrocyte determination before the downregulation of Nrg-1 expression by differentiated cells. Thus one should determine whether soluble ErbB4 is released in a developmentally regulated manner by neural precursors and their derivatives and whether this would result in oligodendrocyte differentiation. Moreover, if mature neurons and their processes express this receptor as our data suggest (Fig. 4D), these cells could release ErbB4 in a regulated way to promote oligodendrocyte differentiation along axons.

In conclusion, our study demonstrates how Nrg-1 promotes the growth of NPs and underlines the importance of Nrg-1 signaling in oligodendrocyte development. This process could occur in two steps. First, Nrg-1 signaling would enhance and maintain the growth of NPs and early oligodendrocyte precursors, and subsequently the regulated release of a soluble Nrg-1 receptor would inhibit mitosis and induce (or permit) oligodendrocyte differen- tiation. Future investigations in vivo and in vitro may help determine whether this hypothesis is correct.

\section{REFERENCES}

Adlkofer K, Lai C (2000) Role of neuregulins in glial cell development. Glia 29:104-111.

Ben-Hur T, Rogister B, Murray K, Rougon G, Dubois-Dalcq M (1998) Growth and fate of PSA-NCAM+ precursors of the postnatal brain. J Neurosci 18:5777-5788.

Bermingham-McDonogh O, McCabe KL, Reh TA (1996) Effects of GGF/neuregulins on neuronal survival and neurite outgrowth correlate with erbB2/neu expression in developing rat retina. Development 122:1427-1438

Bermingham-McDonogh O, Xu YT, Marchionni MA, Scherer SS (1997) Neuregulin expression in PNS neurons: isoforms and regulation by target interactions. Mol Cell Neurosci 10:184-195.

Betz H, Kuhse J, Schmieden V, Laube B, Kirsch J, Harvey RJ (1999) Structure and functions of inhibitory and excitatory glycine receptors. Ann NY Acad Sci 868:667-676.

Brüstle O, Dubois-Dalcq M (2001) CNS stem cells, their gliogenic potential. In: Glial cell development (Jessen K, Richardson WD, eds). New York: Oxford UP, in press.

Burden S, Yarden Y (1997) Neuregulins and their receptors: a versatile signaling module in organogenesis and oncogenesis. Neuron 18:847-855.

Calver AR, Hall AC, Yu WP, Walsh FS, Heath JK, Betsholtz C, Richardson WD (1998) Oligodendrocyte population dynamics and the role of PDGF in vivo. Neuron 20:869-882.

Canoll PD, Musacchio JM, Hardy R, Reynolds R, Marchionni MA, Salzer JL (1996) GGF/neuregulin is a neuronal signal that promotes the proliferation and survival and inhibits the differentiation of oligodendrocyte progenitors. Neuron 17:229-243.

Canoll PD, Kraemer R, Teng KK, Marchionni MA, Salzer JL (1999) $\mathrm{GGF} /$ neuregulin induces a phenotypic reversion of oligodendrocytes. Mol Cell Neurosci 13:79-94.

Carraway KL, Burden SJ (1995) Neuregulins and their receptors. Curr Opin Neurobiol 5:606-612.

Chen X, Levkowitz G, Tzahar E, Karunagaran D, Lavi S, Ben-Baruch N, Leitner O, Ratzkin BJ, Bacus SS, Yarden Y (1996) An immunological approach reveals biological differences between the two NDF/heregulin receptors, ErbB-3 and ErbB-4. J Biol Chem 271:7620-7629.

Ciccolini F, Svendsen CN (1998) Fibroblast growth factor 2 (FGF-2) promotes acquisition of epidermal growth factor (EGF) responsiveness in mouse striatal precursor cells: identification of neural precursors responding to both EGF and FGF-2. J Neurosci 18:7869-7880.

Corfas G, Rosen KM, Aratake H, Krauss R, Fischbach GD (1995) Differential expression of ARIA isoforms in the rat brain. Neuron 14:103-115

Eagleson KL, Daigneau L, Levitt P (1998) The role of ErbB receptor signaling in cell fate decisions by cortical progenitors: evidence for a biased, lineage-based responsiveness to different ligands. Mol Cell Neurosci 12:349-362.

Edlund T, Jessell TM (1999) Progression from extrinsic to intrinsic signaling in cell fate specification: a view from the nervous system. Cell 96:211-224.

Elenius K, Corfas G, Paul S, Choi CJ, Rio C, Plowman GD, Klagsbrun M (1997) A novel juxtamembrane domain isoform of HER4/ErbB4. Isoform-specific tissue distribution and differential processing in response to phorbol ester. J Biol Chem 272:26761-26768.

Fernandez PA, Tang DG, Cheng L, Prochiantz A, Mudge AW, Raff MC (2000) Evidence that axon-derived neuregulin promotes oligodendrocyte survival in the developing rat optic nerve. Neuron 28:81-90.

Flores AI, Mallon BS, Matsui T, Ogawa W, Rosenzweig A, Okamoto T, Macklin WB (2000) Akt-mediated survival of oligodendrocytes induced by neuregulins. J Neurosci 20:7622-7630.

Francis A, Raabe TD, Wen D, DeVries GH (1999) Neuregulins and ErbB receptors in cultured neonatal astrocytes. J Neurosci Res 57:487-494.

Gatti R, Belletti S, Orlandini G, Bussolati O, Dall'Asta V, Gazzola GC (1998) Comparison of annexin V and calcein-AM as early vital markers of apoptosis in adherent cells by confocal laser microscopy. J Histochem Cytochem 46:895-900.

Gavrieli Y, Sherman Y, Ben-Sasson SA (1992) Identification of programmed cell death in situ via specific labeling of nuclear DNA fragmentation. J Cell Biol 119:493-501.

Grinspan JB, Marchionni MA, Reeves M, Coulaloglou M, Scherer SS (1996) Axonal interactions regulate Schwann cell apoptosis in developing peripheral nerve: neuregulin receptors and the role of neuregulins. J Neurosci 16:6107-6118.

Gritti A, Frolichsthal-Schoeller P, Galli R, Parati EA, Cova L, Pagano SF, Bjornson CR, Vescovi AL (1999) Epidermal and fibroblast growth factors behave as mitogenic regulators for a single multipotent stem cell-like population from the subventricular region of the adult mouse forebrain. J Neurosci 19:3287-3297. 
Ho WH, Armanini MP, Nuijens A, Phillips HS, Osheroff PL (1995) Sensory and motor neuron-derived factor. A novel heregulin variant highly expressed in sensory and motor neurons. J Biol Chem 270:14523-14532.

Jessen KR, Mirsky R (1999) Why do Schwann cells survive in the absence of axons? Ann NY Acad Sci 883:109-115.

Keirstead HS, Ben-Hur T, Rogister B, O'Leary MT, Dubois-Dalcq M, Blakemore WF (1999) Polysialylated neural cell adhesion moleculepositive CNS precursors generate both oligodendrocytes and Schwann cells to remyelinate the CNS after transplantation. J Neurosci 19:7529-7536.

Kornblum HI, Yanni DS, Easterday MC, Seroogy KB (2000) Expression of the EGF receptor family members ErbB2, ErbB3, and ErbB4 in germinal zones of the developing brain and in neurosphere cultures containing CNS stem cells. Dev Neurosci 22:16-24.

Mahanthappa NK, Anton ES, Matthew WD (1996) Glial growth factor 2 , a soluble neuregulin, directly increases Schwann cell motility and indirectly promotes neurite outgrowth. J Neurosci 16:4673-4683.

McKinnon RD, Matsui T, Dubois-Dalcq M, Aaronson SA (1990) FGF modulates the PDGF-driven pathway of oligodendrocyte development. Neuron 5:603-614.

Meyer D, Birchmeier C (1995) Multiple essential functions of neuregulin in development. Nature 378:386-390.

Meyer D, Yamaai T, Garratt A, Riethmacher-Sonnenberg E, Kane D, Theill LE, Birchmeier C (1997) Isoform-specific expression and function of neuregulin. Development 124:3575-3586.

Milner R, Anderson HJ, Rippon RF, McKay JS, Franklin RJ, Marchionni MA, Reynolds R, ffrench-Constant C (1997) Contrasting effects of mitogenic growth factors on oligodendrocyte precursor cell migration. Glia 19:85-90.

Mosmann T (1983) Rapid colorimetric assay for cellular growth and survival: application to proliferation and cytotoxicity assays. J Immunol Methods 5.55-63.

Olayioye MA, Neve RM, Lane HA, Hynes NE (2000) The ErbB signaling network: receptor heterodimerization in development and cancer. EMBO J 19:3159-3167.

Pinkas-Kramarski R, Eilam R, Spiegler O, Lavi S, Liu N, Chang D, Wen D, Schwartz M, Yarden Y (1994) Brain neurons and glial cells express Neu differentiation factor/heregulin: a survival factor for astrocytes. Proc Natl Acad Sci USA 91:9387-9391.

Pinkas-Kramarski R, Eilam R, Alroy I, Levkowitz G, Lonai P, Yarden Y (1997) Differential expression of NDF/neuregulin receptors ErbB-3 and ErbB-4 and involvement in inhibition of neuronal differentiation. Oncogene 15:2803-2815.

Raabe TD, Clive DR, Neuberger TJ, Wen D, DeVries GH (1996) Cultured neonatal Schwann cells contain and secrete neuregulins. J Neurosci Res 46:263-270.

Raabe TD, Suy S, Welcher A, DeVries GH (1997) Effect of neu differ- entiation factor isoforms on neonatal oligodendrocyte function. J Neurosci Res 50:755-768.

Reynolds BA, Weiss S (1996) Clonal and population analyses demonstrate that an EGF-responsive mammalian embryonic CNS precursor is a stem cell. Dev Biol 175:1-13.

Reynolds BA, Tetzlaff W, Weiss S (1992) A multipotent EGFresponsive striatal embryonic progenitor cell produces neurons and astrocytes. J Neurosci 12:4565-4574.

Rio C, Buxbaum JD, Peschon JJ, Corfas G (2000) Tumor necrosis factor-alpha-converting enzyme is required for cleavage of erbB4/ HER4. J Biol Chem 275:10379-10387.

Rosenbaum C, Karyala S, Marchionni MA, Kim HA, Krasnoselsky AL, Happel B, Isaacs I, Brackenbury R, Ratner N (1997) Schwann cells express NDF and SMDF/n-ARIA mRNAs, secrete neuregulin, and show constitutive activation of erbB3 receptors: evidence for a neuregulin autocrine loop. Exp Neurol 148:604-615.

Shi J, Marinovich A, Barres BA (1998) Purification and characterization of adult oligodendrocyte precursor cells from the rat optic nerve. J Neurosci 18:4627-4636.

Shinoda J, Nakao J, Iizuka Y, Toba Y, Yazaki T, Kawase T, Uyemura K (1997) Multiple isoforms of neuregulin are expressed in developing rat dorsal root ganglia. J Neurosci Res 50:673-683.

Steiner H, Blum M, Kitai ST, Fedi P (1999) Differential expression of ErbB3 and ErbB4 neuregulin receptors in dopamine neurons and forebrain areas of the adult rat. Exp Neurol 159:494-503.

Svendsen CN, Rosser AE (1995) Neurones from stem cells? Trends Neurosci 18:465-467.

Tsai RY, McKay RD (2000) Cell contact regulates fate choice by cortical stem cells. J Neurosci 20:3725-3735.

Vartanian T, Corfas G, Li Y, Fischbach GD, Stefansson K (1994) A role for the acetylcholine receptor-inducing protein ARIA in oligodendrocyte development. Proc Natl Acad Sci USA 91:11626-11630.

Vartanian T, Goodearl A, Viehover A, Fischbach G (1997) Axonal neuregulin signals cells of the oligodendrocyte lineage through activation of HER4 and Schwann cells through HER2 and HER3. J Cell Biol 137:211-220

Vartanian T, Fischbach G, Miller R (1999) Failure of spinal cord oligodendrocyte development in mice lacking neuregulin. Proc Natl Acad Sci USA 96:731-735.

Wolpowitz D, Mason TBA, Dietrich P, Mendelsohn M, Talmage DA, Role LW (2000) Cysteine-rich domain isoforms of the neuregulin-1 gene are required for maintenance of peripheral synapses. Neuron 25:79-91.

Yang X, Kuo Y, Devay P, Yu C, Role L (1998) A cysteine-rich isoform of neuregulin controls the level of expression of neuronal nicotinic receptor channels during synaptogenesis. Neuron 20:255-270.

Zhou W, Carpenter G (2001) Heregulin-dependent trafficking and cleavage of ErbB-4. J Biol Chem 275:34737-34743. 